\title{
THE
}

2008

\section{Observations of Kuroshio flow variations in the East China Sea}

\author{
Magdalena Andres \\ University of Rhode Island \\ Mark Wimbush \\ University of Rhode Island, mwimbush@uri.edu \\ J.-H. Park \\ University of Rhode Island \\ K.-I. Chang \\ B.-H. Lim
}

See next page for additional authors

Follow this and additional works at: https://digitalcommons.uri.edu/gsofacpubs

Terms of Use

All rights reserved under copyright.

\section{Citation/Publisher Attribution}

Andres, M., M. Wimbush, J.-H. Park, K.-I. Chang, B.-H. Lim, D. R. Watts, H. Ichikawa, and W. J. Teague (2008), Observations of Kuroshio flow variations in the East China Sea, J. Geophys. Res., 113, C05013, doi:10.1029/2007JC004200.

Available at: https://doi.org/10.1029/2007JC004200

This Article is brought to you for free and open access by the Graduate School of Oceanography at DigitalCommons@URI. It has been accepted for inclusion in Graduate School of Oceanography Faculty Publications by an authorized administrator of DigitalCommons@URI. For more information, please contact digitalcommons-group@uri.edu. 


\section{Authors}

Magdalena Andres, Mark Wimbush, J.-H. Park, K.-I. Chang, B.-H. Lim, D. Randolph Watts, H. Ichikawa, and W. J. Teague 


\title{
Observations of Kuroshio flow variations in the East China Sea
}

\author{
M. Andres, ${ }^{1}$ M. Wimbush, ${ }^{1}$ J.-H. Park, ${ }^{1}$ K.-I. Chang, ${ }^{2}$ B.-H. Lim, ${ }^{2}$ D. R. Watts, ${ }^{1}$ \\ H. Ichikawa, ${ }^{3}$ and W. J. Teague ${ }^{4}$ \\ Received 5 March 2007; revised 4 October 2007; accepted 29 December 2007; published 10 May 2008.
}

[1] Kuroshio velocity structure and transport in the East China Sea (ECS) were investigated as part of a 23-month study using inverted echo sounders and acoustic Doppler current profilers (ADCPs) along the regularly sampled PN-line. Flow toward the northeast is concentrated near the continental shelf with the mean surface velocity maximum located $30 \mathrm{~km}$ offshore from the shelf break (taken as the $170 \mathrm{~m}$ isobath). There are two regions of southwestward flow: a deep countercurrent over the continental slope beneath the Kuroshio axis and a recirculation offshore which extends throughout the whole water column. There is a bimodal distribution to the depth of maximum velocity with occurrence peaks at the surface and $210 \mathrm{dbar}$. When the maximum velocity is located within the top $80 \mathrm{~m}$ of the water column, it ranges between $0.36 \mathrm{~m} / \mathrm{s}$ and $2.02 \mathrm{~m} / \mathrm{s}$; when the maximum velocity is deeper than $80 \mathrm{~m}$, it ranges between $0.31 \mathrm{~m} / \mathrm{s}$ and $1.11 \mathrm{~m} / \mathrm{s}$. The 13-month mean net absolute transport of the Kuroshio in the ECS is $18.5 \pm 0.8 \mathrm{~Sv}$ (standard deviation, $\sigma=4.0 \mathrm{~Sv}$ ). The mean positive and negative portions of this net flow are $24.0 \pm 0.9 \mathrm{~Sv}$ and $-5.4 \pm 0.3 \mathrm{~Sv}$, respectively.

Citation: Andres, M., M. Wimbush, J.-H. Park, K.-I. Chang, B.-H. Lim, D. R. Watts, H. Ichikawa, and W. J. Teague (2008), Observations of Kuroshio flow variations in the East China Sea, J. Geophys. Res., 113, C05013, doi:10.1029/2007JC004200.

\section{Introduction}

[2] The Kuroshio is a western boundary current, serving as the return flow for the wind-driven circulation of the North Pacific Subtropical Gyre. Its source is the North Equatorial Current which bifurcates off the Philippines [Nitani, 1972]. The northward flowing branch of this bifurcation, the Kuroshio, sometimes loops into the South China Sea before passing east of Taiwan. There, part diverts to the east forming the Ryukyu Current [Yuan et al., 1998; Ichikawa et al., 2004; Zhu et al., 2003], which flows along the eastern side of the Ryukyu Island chain, while the remainder enters the East China Sea (ECS) over the Ilan Ridge (sill depth $\sim 775 \mathrm{~m}$ [Choi et al., 2002]) forming the ECS Kuroshio. The Ryukyu Island chain separates the ECS from the Philippine Basin (Figure 1). There is one deep channel in this chain, the Kerama Gap south of Okinawa, with a sill depth of about $1000 \mathrm{~m}$ [Sibuet et al., 1995]. In the ECS, the Kuroshio flows mainly just seaward of the shelf break before leaving through the Tokara Strait, which is divided into two sections by a seamount (summit $\sim 320 \mathrm{~m}$ depth); the northern section reaches $\sim 460 \mathrm{~m}$ depth while the southern section reaches $\sim 1400 \mathrm{~m}$ [Oka and Kawabe,

\footnotetext{
${ }^{1}$ Graduate School of Oceanography, University of Rhode Island, Narragansett, Rhode Island, USA.

${ }^{2}$ Research Institute of Oceanography/School of Earth and Environmental Sciences, Seoul National University, Seoul, South Korea.

${ }^{3}$ Institute of Observational Research for Global Change, Japan Agency for Marine-Earth Science and Technology, Yokosuka City, Japan.

${ }^{4}$ Naval Research Laboratory, Stennis Space Center, Mississippi, USA.

Copyright 2008 by the American Geophysical Union. 0148-0227/08/2007JC004200
}

2003]. East of the Tokara Strait, the Ryukyu Current and the Kuroshio rejoin and flow northeastward south of Japan until they leave the coast as a free jet known as the Kuroshio Extension. A schematic of the Kuroshio path inside and near the ECS is shown in Figure 1.

[3] Previous studies of Kuroshio velocity structure in the ECS have reported northeastward Kuroshio surface currents reaching speeds of 3.5 knots [Su et al., 1990]. A subsurface velocity maximum at about $200 \mathrm{~m}$ depth has been detected in some velocity sections northwest of Okinawa [e.g., Ito et al., 1995; Ichikawa and Beardsley, 1993; Su et al., 1990, and references therein]. However, a subsurface maximum is absent in the mean absolute velocity section of Oka and Kawabe [2003] and it is unclear whether this is related to instrument spacing or to the transience of the subsurface maximum. The Kuroshio lies over the slope and its position has a standard deviation of about $10 \mathrm{~km}$ [e.g., Yamashiro and Kawabe, 2002] due to Kuroshio meanders inside the ECS. The amplitudes of these meanders are much smaller than the meander amplitudes south of Japan and in the Kuroshio Extension.

[4] A southwestward flowing countercurrent beneath the Kuroshio has been reported [e.g., Ito et al., 1995; James et al., 1999]. Moored current-meter data collected during 2004-2006 along the slope in water about $700 \mathrm{~m}$ deep show southwestward flow in the mean, about $100 \mathrm{~m}$ above the seafloor (H. Nakamura et al., Deep countercurrent beneath the Kuroshio in the Okinawa Trough of the East China Sea, submitted to Journal of Geophysical Research, 2008). The countercurrent transport and structure, however, are not well resolved, since these are a few discrete point measurements. 


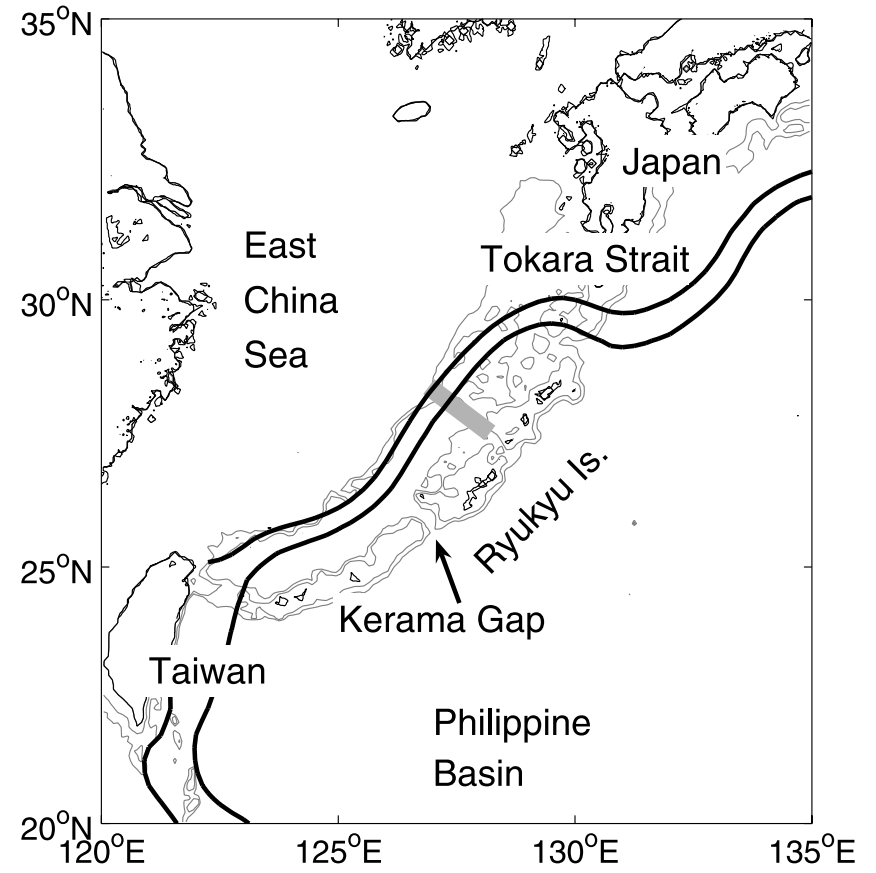

Figure 1. Regional ECS map. Kuroshio path, shown with heavy black lines, is estimated from 2002 to 2004 Mean Absolute Dynamic Topography produced by Ssalto/Duacs and distributed by AVISO with support from Cnes. Array location shown as grey rectangle. Depth contours in light grey at $500 \mathrm{~m}$ and $1000 \mathrm{~m}$.

[5] Southwestward flow has also been reported between the Kuroshio and the Ryukyu Islands forming a recirculation [e.g., Oka and Kawabe, 2003; James et al., 1999]. This flow is typically strongest at the surface where southwestward surface currents can reach 2 knots [Su et al., 1990].

[6] Previous studies of Kuroshio transport in the ECS include calculations for the period between 1986 and 1988 made from 39 hydrographic sections referenced with surface current data measured by ADCP and Geomagnetic Electrokinetograph (GEK) [Ichikawa and Beardsley, 1993]. The mean northeastward absolute transport for these sections was 23.7 Sv. Johns et al. [2001] measured the transport just upstream of the ECS east of Taiwan between September 1994 and May 1996 along a WOCE line, using moored current meters and acoustic Doppler current profilers (ADCPs) and determined that the 20-month mean absolute net transport was 21.5 Sv. James et al. [1999] deployed inverted echo sounders (IESs) north of Okinawa to measure acoustic travel time and bottom pressure from August 1991 until October 1992. Their study, however, focused on the characteristics of ECS Kuroshio meanders instead of transport, because current measurements were unavailable for referencing.

[7] The previous studies of Kurohsio position and velocity structure inside the ECS are limited spatially or temporally. There has been no long-term continuous measurement of absolute transport within the ECS; reports of mean transports in the ECS have relied on averaging snapshots taken over many years. Here we present a 23 -month time series of Kuroshio net absolute transport in the ECS. We also report on the time-and-space varying velocity structure of the Kuroshio over the last 13 of these months (when measurements were more complete) and calculate the corresponding positive and negative transport time series. In addition to quantifying the Kuroshio volume transports, we investigate their time variabilities as well as those of Kuroshio position and width.

\section{Data}

[8] The primary data sources for this investigation are 11 IESs which were deployed in the Okinawa Trough region of the ECS for nearly 2 years and two ADCPs deployed nearby on the outer shelf for 7-13 months (Figure 2, Table 1).

\subsection{IES}

[9] Eleven IESs were deployed on the seafloor across the Kuroshio in two parallel lines separated by $40 \mathrm{~km}$ (C-line and $\mathrm{P}$-line with six and five instruments, respectively) from December 2002 until November 2004. The C-line nearly coincided with the PN-line along which hydrographic data are regularly collected four times per year by the Nagasaki Marine Observatory of the Japan Meteorological Agency. Horizontal spacing of the instruments varied from about $20 \mathrm{~km}$ beneath the main Kuroshio axis at the northwestern end of the line to $40 \mathrm{~km}$ at the southeastern end. Each P-line instrument (PIES) was equipped with a Digiquartz pressure sensor, and each C-line instrument (CPIES) was equipped not only with the pressure sensor but also an RCM11 Aanderaa current sensor moored $51 \mathrm{~m}$ above the bottom. These instruments measured round trip, bottom-to-surface acoustic-traveltime $(\tau)$, bottom pressure, and bottom temperature every hour. In addition, the upstream instruments (C-line) made hourly measurements of current velocity and temperature $51 \mathrm{~m}$ above the bottom. The data set is complete except for the current record and about $1 / 3$ of the pressure record at site $\mathrm{C} 5$. The velocity cross section and transport results discussed here focus on the $\mathrm{C}$-line; however, the $\tau$ measurements from the P-line are used in the optimal interpolation mapping procedure described in section 3.1.2.

\subsection{ADCP}

[10] The portion of the Kuroshio which flowed in waters shallower than $550 \mathrm{~m}$, near or over the shelf, was outside the region sampled by the IESs. For part of the 2-year IES deployment, this portion of the flow was measured with two bottom-mounted ADCPs on the shoreward extension of the C-line. Details of the velocity structure measured by the ADCPs are reported elsewhere [Lim, 2008]. Here the ADCP data are mainly used to calculate the transport of the Kuroshio on the upper slope and shelf.

[11] The ADCP data set is incomplete spatially and temporally. Section 3.2 presents results of various methods used to extrapolate these data in space and time with the details given in Appendix A. The shallower ADCP (A1) was operational for 7 months from May 2004 until November 2004. This instrument measured velocity from $152 \mathrm{~m}$ depth $(0.5 \mathrm{~m}$ above the seafloor $)$ to $30 \mathrm{~m}$ below the surface with $4 \mathrm{~m}$ bin sizes. The deeper instrument (A2) was operational for 13 months from October 2003 until November 2004 and measured velocities from $285 \mathrm{~m}$ depth 


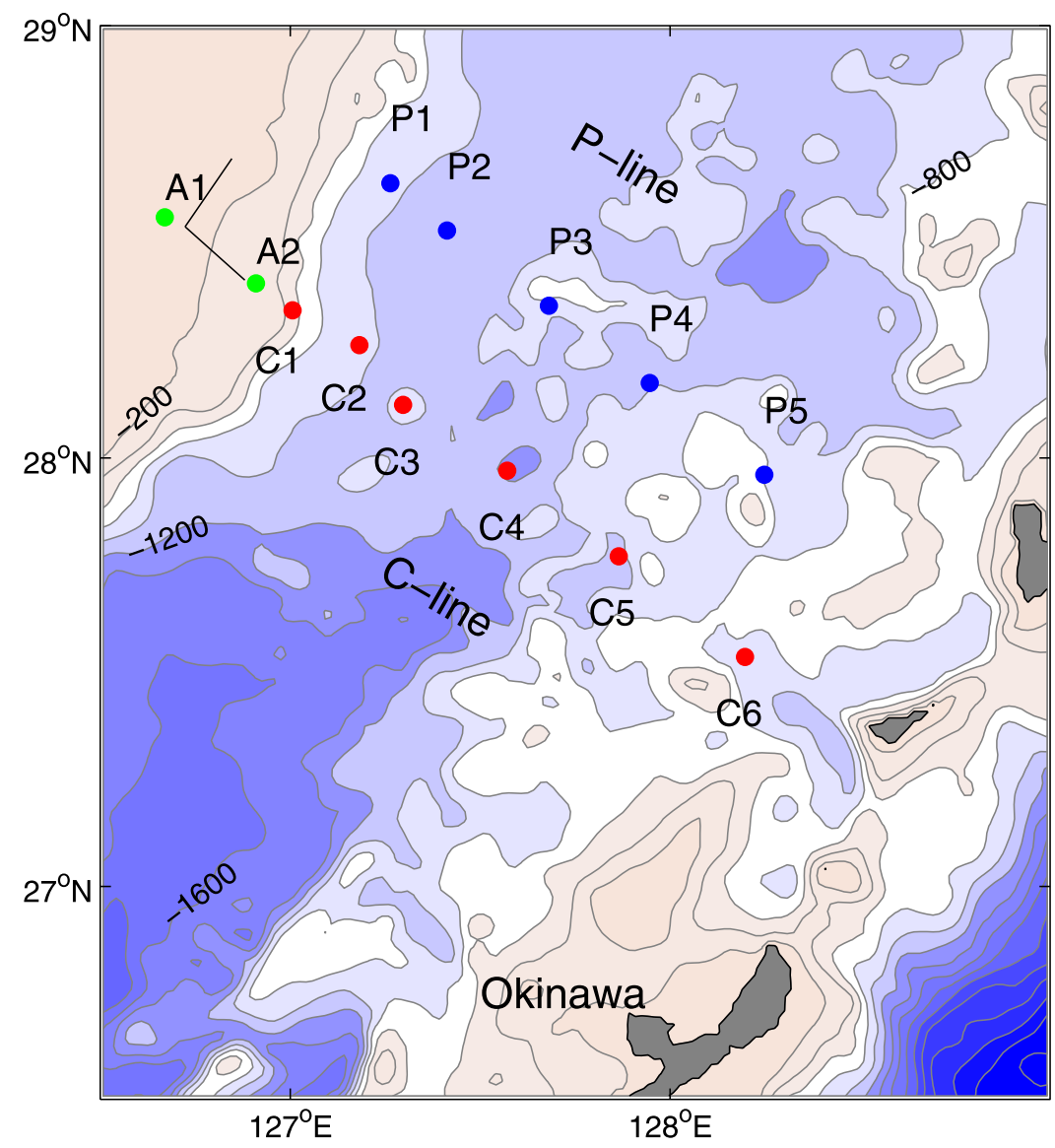

Figure 2. Array map. Green dot $=\mathrm{ADCP}$; red $=$ CPIES; blue $=$ PIES. Contour interval is $200 \mathrm{~m}$. Black lines show origin as well as cross-stream $\left(x, 128^{\circ}\right)$ and downstream $\left(y, 38^{\circ}\right)$ directions.

(5 $\mathrm{m}$ above the seafloor) to $179 \mathrm{~m}$ below the surface with $8 \mathrm{~m}$ bin sizes.

\subsection{Processing}

[12] Acoustic-travel-time data, $\tau$, measured at the seafloor by each instrument, were converted to travel time referenced to a common pressure level, $\tau_{\text {ref }}$, by the following method. First the instrument's pressure level was determined from the mean of its pressure record. Then from historic hydrographic profiles collected in the ECS over the last 80 years (data from North Pacific Hydrobase [Macdonald et al., 2001] and the Nagasaki Marine Observatory of the Japan Meteorological Society) we selected 1833 which reached at least $700 \mathrm{dbar}$. From these profiles two synthetic travel times were calculated: (1) that between $700 \mathrm{dbar}$ and the surface $\left(\tau_{\text {ref }}\right)$, and (2) that between the instrument pressure level and the surface $\left(\tau_{\mathrm{p}}\right)$. The linear relationship between $\tau_{\text {ref }}$ and $\tau_{\mathrm{p}}$ was determined by least squares fitting. This relationship was then used to convert the instrument's measured $\tau$ time series to a corresponding $\tau_{\text {ref }}$ time series. The whole procedure was repeated for each IES instrument.

[13] All $\tau_{\text {ref, pressure, and current (from CPIES or }}$ ADCP) data were lowpass filtered using a second-order Butterworth filter with 48-hour cutoff period run forward and backward. The records were then subsampled at 12-hour intervals. Details about the data processing, including removal of occasional "jumps" (probably due to bottom-fishing boats dragging the IESs), detiding pressure
Table 1. Locations, Mean Pressures, and Measured Near-Bottom Currents of Array Instruments

\begin{tabular}{|c|c|c|c|c|c|c|}
\hline & $\begin{array}{l}\text { Lat. } \\
\left({ }^{\circ} \mathrm{N}\right)\end{array}$ & $\begin{array}{c}\text { Long. } \\
\left({ }^{\circ} \mathrm{E}\right)\end{array}$ & $\begin{array}{c}x \text { Position }^{\mathrm{a}} \\
(\mathrm{km})\end{array}$ & $\begin{array}{c}\text { Pressure }^{b} \\
(\mathrm{dbar})\end{array}$ & \multicolumn{2}{|c|}{$\begin{array}{r}v(\mathrm{~cm} / \mathrm{s}) \\
\text { Mean Std. }^{\mathrm{c}}\end{array}$} \\
\hline \multicolumn{7}{|c|}{$A D C P$} \\
\hline A1 & 28.558 & 126.670 & -5.6 & 152 & 1.5 & 11.0 \\
\hline A2 & 28.405 & 126.910 & 23.3 & 286 & -0.3 & 15.3 \\
\hline \multicolumn{7}{|c|}{ CPIES } \\
\hline $\mathrm{C} 1$ & 28.343 & 127.006 & 35.0 & 554 & -1.3 & 7.5 \\
\hline $\mathrm{C} 2$ & 28.262 & 127.182 & 54.1 & 1006 & -2.8 & 5.6 \\
\hline $\mathrm{C} 3$ & 28.123 & 127.297 & 72.5 & 1131 & 10.7 & 6.6 \\
\hline $\mathrm{C} 4$ & 27.971 & 127.571 & 104.2 & 1339 & -0.3 & 2.9 \\
\hline C5 & 27.771 & 127.864 & 140.6 & 1115 & & \\
\hline C6 & 27.540 & 128.197 & 182.6 & 891 & -3.7 & 2.7 \\
\hline \multicolumn{7}{|c|}{ PIES } \\
\hline P1 & 28.637 & 127.264 & 34.7 & 1033 & & \\
\hline $\mathrm{P} 2$ & 28.527 & 127.412 & 53.6 & 1121 & & \\
\hline P3 & 28.353 & 127.681 & 86.3 & 856 & & \\
\hline P4 & 28.174 & 127.946 & 119.1 & 1080 & & \\
\hline P5 & 27.961 & 128.248 & 157.2 & 750 & & \\
\hline
\end{tabular}

${ }^{\mathrm{a}}$ Here $\mathrm{x}$ is seaward distance (toward $128^{\circ}$ ) with the origin taken as the shelf break ( $170 \mathrm{~m}$ isobath) on the C-line: $28.536^{\circ} \mathrm{N}, 126.723^{\circ} \mathrm{E}$ (see Figure 2).

${ }^{\mathrm{b}}$ Pressures are mean pressures recorded at instrument locations: A $10.5 \mathrm{~m}$, A2 $5 \mathrm{~m}$, and C1-6/P1-5 $1 \mathrm{~m}$ above the seafloor.

${ }^{\mathrm{c}}$ Here $v$ is the downstream (rotated $38^{\circ}$ clockwise from $0^{\circ}$ true) velocity component measured near-bottom: A1 $6 \mathrm{~m}$, A2 $15 \mathrm{~m}$, and C1-6 $51 \mathrm{~m}$, above the seafloor. 

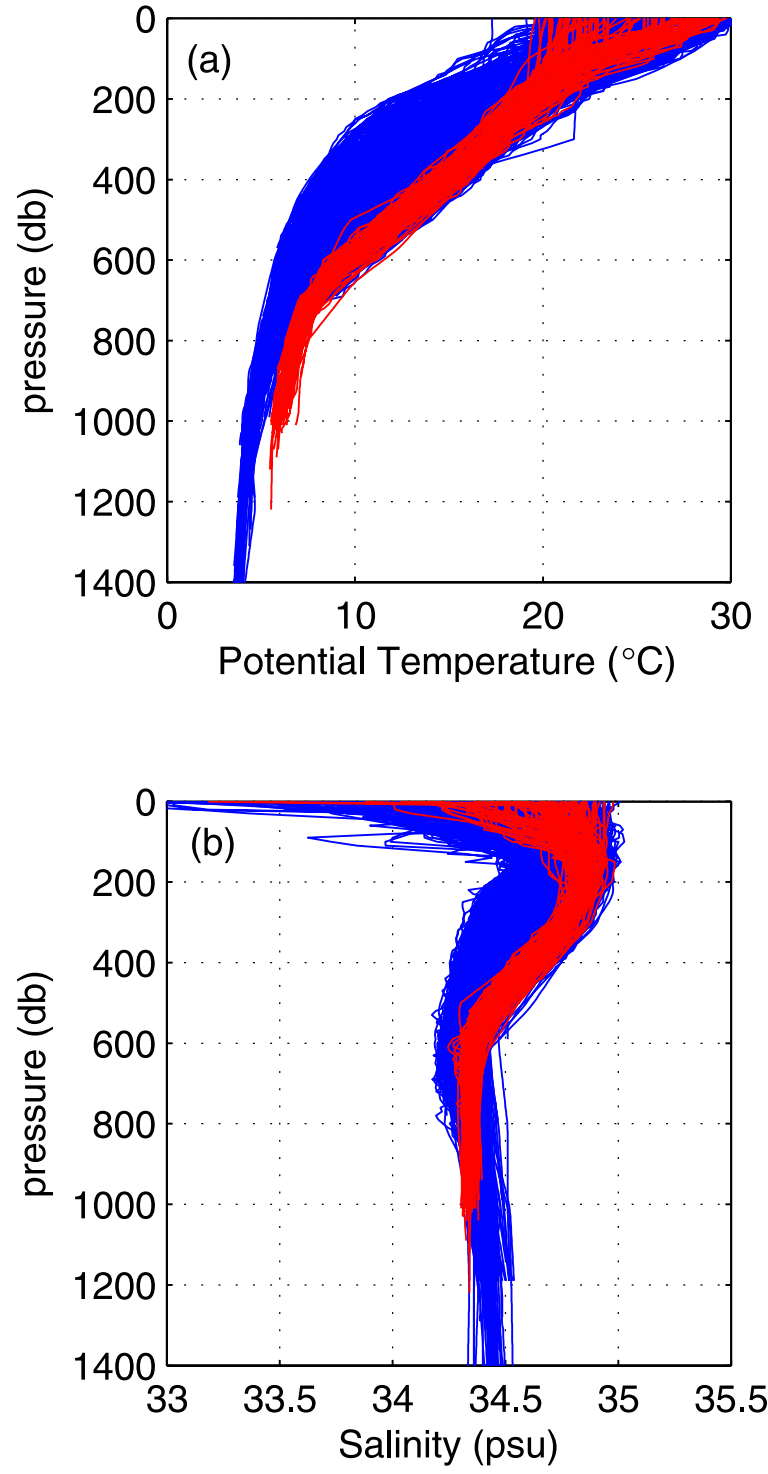

Figure 3. ECS hydrocast profiles of (a) temperature and (b) salinity. Red are 113 profiles from Okinoerabushima Basin used to construct the localized GEM for C6. Blue are 1720 profiles from the rest of the ECS used to construct the main ECS GEM.

records and correction of pressure-sensor drift, are described in detail in a data report [Andres et al., 2005].

[14] Current data were corrected for the local magnetic declination (roughly $5^{\circ} \mathrm{W}$ ) and rotated $38^{\circ}$ clockwise so that $U$ is the offshore cross-stream $(x)$ velocity component and $V$ is the downstream $(y)$ velocity component. This rotation is consistent with the orientation of the PN-line (Figure 2).

\section{Obtaining Velocity Fields and Transports 3.1. Off-Shelf: Interpreting the IES Data}

\subsubsection{GEM Fields}

[15] For sea water, sound speed and specific volume anomaly $(\delta)$ both depend only on temperature, salinity, and pressure. As a result, in many regions $\tau_{\text {ref }}$ can be used as a proxy for a water column's $\delta$ profile [He et al., 1998].
This relationship of $\delta$ to $\tau_{\text {ref }}$ and pressure is called the Gravest Empirical Mode (GEM) [Sun and Watts, 2001], and the GEM empirical lookup table typically resembles firstmode baroclinic variations in the water-column density distribution. In strong baroclinic current regions the GEM usually represents the pycnocline sloping across the current system and accounts for most of the observed variability in $\delta$ [Willeford, 2001; Meinen, 2001; Sun and Watts, 2001; Book et al., 2002; Rodrigues, 2004; Park et al., 2005]. Other sources of variability, such as internal waves or bottom-intensified topographic waves, can exist without being represented by the GEM.

[16] In many applications, a single GEM field is used as a $\delta$-lookup table for a given region, but in the ECS, we constructed two separate fields: a localized GEM for a small region around $\mathrm{C} 6$ and a main GEM for the rest of the IES sites. Detailed bathymetry data with 1-minute resolution [Choi et al., 2002] reveal that deep water near site C6 (883 $\mathrm{m}$ depth) is isolated from similar-depth water in the rest of the ECS, because it is situated within a small Y-shaped basin with a sill depth of $\sim 800 \mathrm{~m}$ and a maximum bottom depth of $\sim 1200 \mathrm{~m}$ (Figure 2). This basin lies just off the west coast of the island of Okinoerabushima in the Ryukyu Island chain, and thus we call it the Okinoerabushima Basin. A comparison of temperature profiles from the 1833 historic ECS hydrographic profiles shows that water within this basin is warmer than water at the same depths elsewhere in the ECS, typically about $1.5^{\circ} \mathrm{C}$ warmer at 850 dbar (Figure 3). Hence, only the 1720 ECS profiles from outside the basin region are used to compute the main ECS GEM, while the localized GEM is calculated exclusively from the 113 hydrocasts taken within the basin region. Details of generating the GEM lookup tables are reported in Andres et al. [2005]. Errors in the GEM lookup table between 100 and 200 dbar caused by second-mode internal tides are reported by Park et al. [2006], but, as they point out, such errors are effectively removed by 48 -hour lowpass filtering of the data.

\subsubsection{Off-Shelf: Calculating the Transport}

[17] The lowpass filtered $\tau_{\text {ref }}$ data from the CPIESs and PIESs were gridded at $10 \mathrm{~km}$ spacing in $x$ and $y$ using optimal interpolation (OI) [Bretherton et al., 1976; Watts et al., 1989] with an empirically determined correlation length scale for $\tau_{\text {ref }}$ of $55 \mathrm{~km}$ and the assumption of horizontally nondivergent flow. For flow over sloping topography, this assumption results in isopycnals which are cut off rather than compressed by the topography. Using the GEM relationship, a time series of C-line $\delta$ cross sections was generated from the mapped $\tau_{\text {ref. These cross sections were }}$ used with the thermal-wind equation,

$$
\frac{\partial \nu}{\partial z}=-\frac{g}{\rho f} \frac{\partial \rho}{\partial x}
$$

to calculate time series of the Kuroshio's downstream baroclinic velocity, $v$, and transport both referenced to 700 dbar (Figure 4, upper line). Here $z$ is in the upward vertical direction, $g$ is gravity, $\rho$ density, and $f$ the Coriolis parameter.

[18] In order to calculate the barotropic velocity (i.e., the absolute velocity at 700 dbar) and its corresponding transport across the $\mathrm{C}$-line, one needs to know the horizontal 


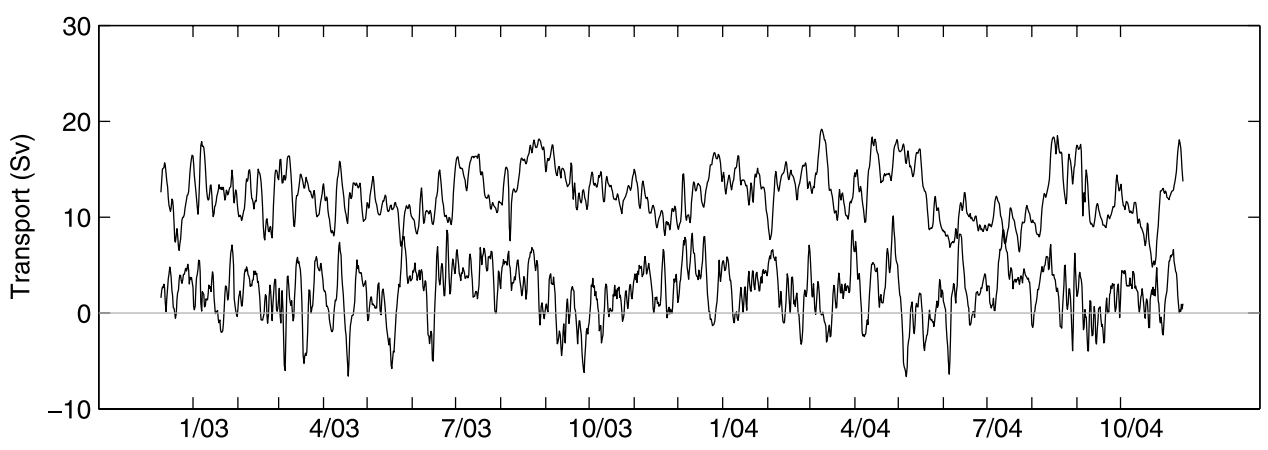

Figure 4. Off-shelf transport. Calculated as described in the text from CPIESs between $x=35 \mathrm{~km}$ and $\mathrm{x}=195 \mathrm{~km}$ where $\mathrm{x}=0$ at the shelf break (170 $\mathrm{m}$ isobath). In order to capture the transport flowing between the Ryukyu Islands and the most offshore instrument (C6 at $\mathrm{x}=182.6 \mathrm{~km}), \tau_{\text {ref }}$ was OI mapped slightly beyond the instrument array. This $12.4 \mathrm{~km}$ extrapolation is over a short distance relative to the $\tau_{\text {ref }}$ correlation length scale of $55 \mathrm{~km}$. Upper line is the baroclinic transport referenced to $700 \mathrm{dbar}$. Lower line is the barotropic transport. Tick marks denote the beginning of each month.

pressure gradient on an appropriate geopotential (level) surface. Since the depth of each instrument was not known with sufficient accuracy (because pressure sensors cannot deliver 1-to-10 ppm absolute accuracy), time-averaged current data from the CPIES current sensors were used to reference or "level" the pressure data.

[19] Because of significant deep geostrophic shear in the ECS, the following method was used to "level" the C-line instruments. For each instrument site, $i$, the mean downstream velocity, $\bar{V}_{i}$, at any level, is related to the mean pressure, $\bar{P}_{i}$, at that level by geostrophy,

$$
\bar{V}_{i}=\frac{1}{\rho f} \frac{\partial \bar{P}_{i}}{\partial x},
$$

where the derivative is taken along the geopotential (level) surface. The velocity at the $700 \mathrm{~m}$ level for each instrument location can be written as the velocity measured by the current sensor plus the velocity difference between the depth, $d_{i}$, of the current sensor and the $700 \mathrm{~m}$ surface. Thus in the mean, for the y-component,

$$
\bar{V}_{i}=\frac{1}{T} \sum_{t=0}^{T}\left[v_{i}(t)+\int_{-d_{i}}^{-700 m} \frac{\partial \nu_{i}(z, t)}{\partial z} d z\right]
$$

where $t$ is time, $T$ the duration of the measurements, $v_{i}$ the $\mathrm{y}$-component of velocity measured by the current sensor, and the velocity shear in the last term is determined from the travel-time measurements using the GEM and equation (1). So using equations (2) and (3) and OI with an empirically determined correlation length scale for pressure of $35 \mathrm{~km}$, the mean (relative) pressure on the chosen geopotential surface at each site, $\bar{P}_{i}$, was calculated from the measured current velocity, $v_{i}(t)$, and acoustic-travel-time, $\tau_{i}(t)$. By comparison of this calculated mean pressure with the mean of the measured pressure record, $\bar{p}_{i}$, a leveling constant, $L C$, was determined for each instrument and added to the respective pressure record:

$$
L C_{i}=\bar{P}_{i}-\bar{p}_{i}
$$

[20] With a second OI step, this time using the current sensor measurements and the "leveled" pressure measurements, $P_{i}=p_{i}+L C_{i}$, the barotropic velocity and transport were calculated (Figure 4, lower line). The approximation made here is that the barotropic velocity, which is defined in this work as the velocity at $700 \mathrm{dbar}$, is equivalent to the velocity at $700 \mathrm{~m}$. The difference in velocity between $700 \mathrm{~m}$ and $700 \mathrm{dbar}$ is very small, because both $\Delta z$ and $\partial v / \partial z$ are small.

\subsection{Shelf and Upper Slope: Interpreting the ADCP Data}

[21] The ADCPs were deployed for only the last 13 months of the 23-month period during which CPIES data were collected. Even when the ADCPs were operational, current velocities were not measured in the topmost $30 \mathrm{~m}$ and $179 \mathrm{~m}$ at sites A1 and A2, respectively. In an attempt to establish reasonable estimates of the Kuroshio transport over the upper slope and shelf (i.e., shallower than $550 \mathrm{~m}$ ) for the entire 23-month period, several extrapolation methods were attempted. Two of these are spatial extrapolations (filling in the tops of the velocity profiles) and one is temporal (extending into the first 10 months of IES deployment for which no contemporaneous ADCP data are available). In all cases, once the velocity profiles were determined, they were mapped onto a regular grid with $10 \mathrm{~km}$ horizontal spacing by linear interpolation. Zero velocity was assumed $15 \mathrm{~km}$ shoreward of the shelf break. The gridded velocities were then integrated to calculate the transport over the outer shelf and upper slope between $x=$ $-15 \mathrm{~km}$ (130 m depth) and $x=35 \mathrm{~km}$ (550 m depth), the position of $\mathrm{C} 1$. Because of low velocities at site $\mathrm{A} 1$ and shallow water shoreward of this, the transport calculations are insensitive to the location of the zero velocity point. Specifically, moving this point $10 \mathrm{~km}$ further shoreward increases the mean transport by only $0.1 \mathrm{~Sv}$.

\subsubsection{Spatial Extrapolation}

[22] The spatial extrapolation methods were (1) vertical extension with a GEM and (2) a horizontal smoothing method. These spatial extrapolation methods are described in Appendix A. Resulting time series of transport over the upper slope and shelf are plotted in Figure 5. It is encouraging that the vertical-extension and horizontal-smoothing 


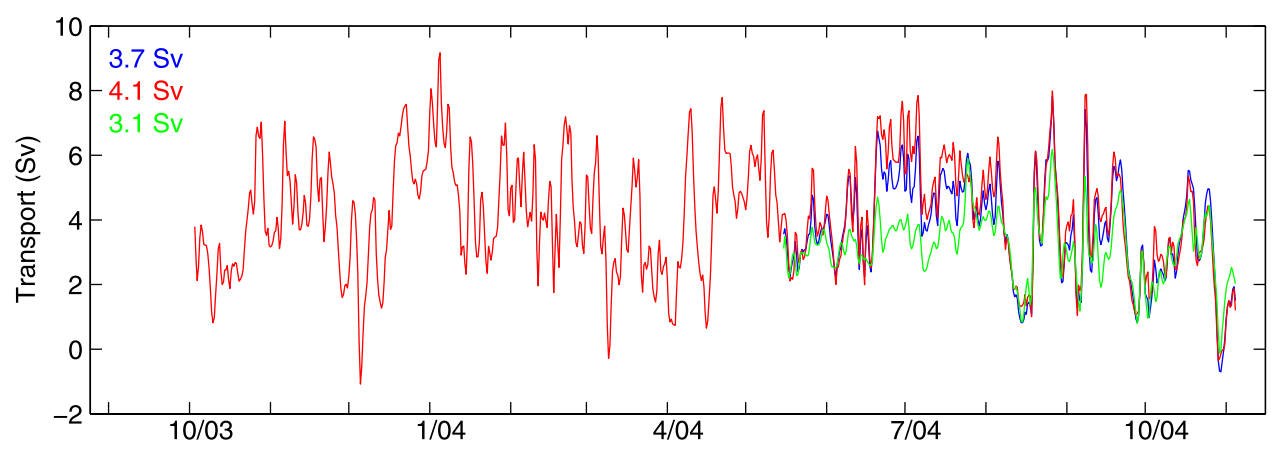

Figure 5. Net transport on the upper slope and shelf (i.e., $<35 \mathrm{~km}$ ) determined from ADCPs, from vertical extension method using data from A1 and A2 (blue), A2 only (red) and from horizontal smoothing method (green). Tick marks denote the beginning of each month. In upper left corner, mean values are listed in their respective colors.

methods generally resulted in similar transport time series even though the procedures are entirely different. The rms difference between the transports calculated by these two methods is 1.0 Sv. Occasionally, however, the vertical extension method gave higher shelf transports (e.g., around the beginning of July 2004 in Figure 5). During these times vertical profiles of velocity (figure not shown) generated by the horizontal smoothing method appear unrealistic, with velocities changing abruptly with depth. Also, during these times, the vertical extension method suggests there is a velocity maximum near A2. The horizontal smoothing method simply cannot reproduce situations where there is such a maximum between $\mathrm{A} 1$ and $\mathrm{C} 1$. Consequently, we choose the vertical extension method as the more realistic method of spatial extrapolation.

[23] Velocities measured at A1 were typically small (usually of order $0.2 \mathrm{~m} / \mathrm{s}$ or less) and thus the transport calculations are insensitive to A1 measurements. The vertical extension method was attempted both with and without the A1 velocity measurements as inputs to the OI calculations, and the resulting transports are nearly the same (Figure 5, blue and red lines, rms difference $0.6 \mathrm{~Sv}$ ). By using only the A2 measurements, we obtain a transport time series for 13 months instead of just the 7 months of A1 operation.

\subsubsection{Temporal Extrapolation}

[24] The majority (77\%) of the Kuroshio mean net transport was measured by the CPIESs with the remainder (that on the upper slope and shelf) measured by the ADCP(s). In order to obtain an estimate of this flow for the first 10 months of CPIES deployment, during which the ADCPs were not operational, the position and strength of the Kuroshio were established using off-shelf velocities from the CPIESs. Then an empirically determined analytical shape formula was used to extrapolate the net transport over the upper slope and shelf. The method is described in Appendix A. Figure 6 shows that during the 13 months when ADCP data were available, the transport values calculated by this extrapolation agree reasonably well with 20 -d low-pass filtered net transports determined from the ADCP data (rms difference $=$ 1.4 Sv). This extrapolation of net transport enables the analysis of seasonal variability by extending the time series to nearly 2 years. However, since the method oversimplifies the complex time-varying velocity structure of the Kuroshio, we use it to infer net transport only and not to extrapolate the velocity structure or to calculate the positive and negative pieces of the net transport.

\section{Results}

[25] In this section we report on the mean and variability of the observed velocity field and the transports.

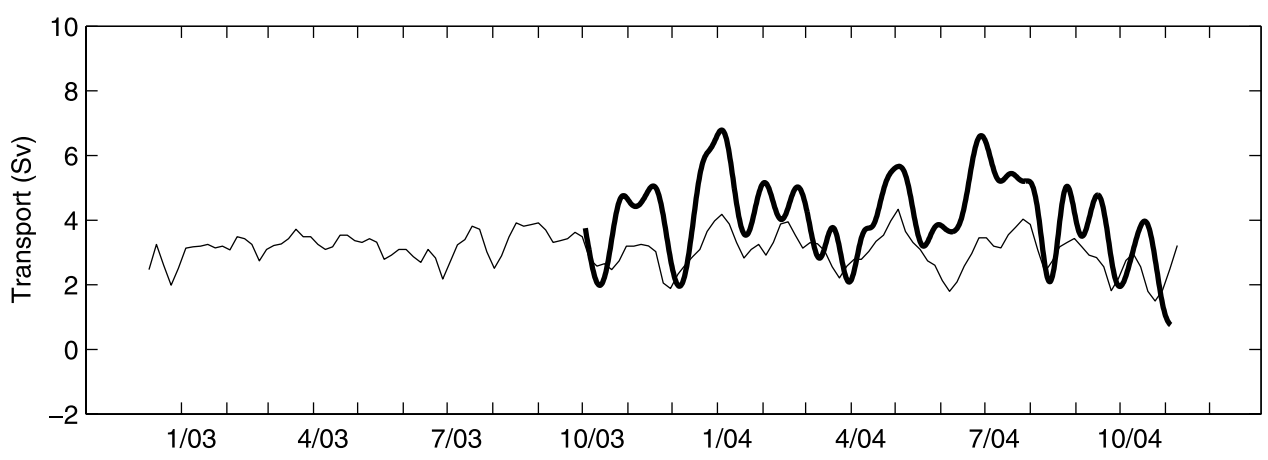

Figure 6. Net transport on the upper slope and shelf (i.e., $\mathrm{x}<35 \mathrm{~km}$ ) from the analytic-shape method (thin line) and 20-d lowpass filtered transport from the vertical extension method applied to A2 ADCP data (thick line). Tick marks denote the beginning of each month. 13-month mean values are $3.0 \mathrm{~Sv}$ and 4.1 Sv for the analytic shape and 20-d lowpassed methods, respectively; the 23-month mean for the transport derived from the analytic-shape method is $3.1 \mathrm{~Sv}$. 


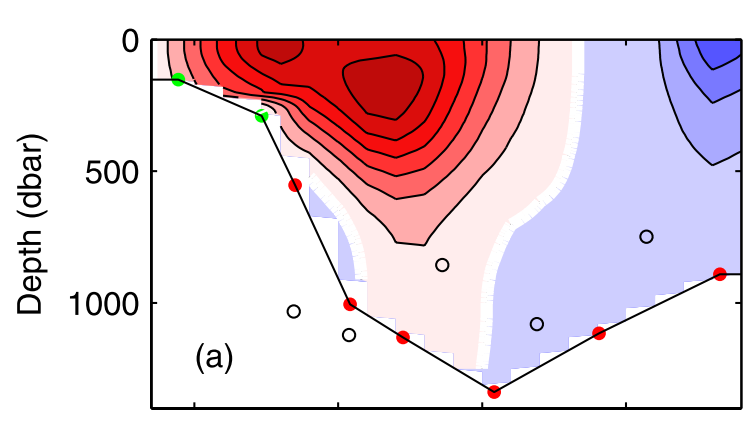

$\mathrm{m} / \mathrm{s}$

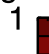

5

0.5

0

$-0.5$

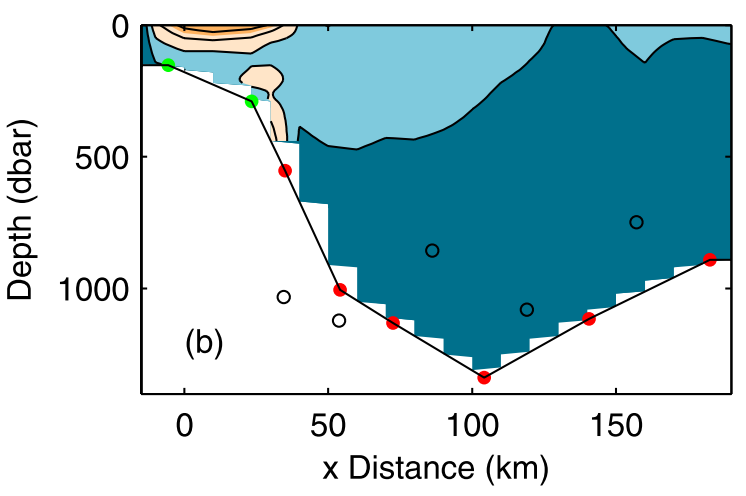

0.4

0.3

0.2

0.1

0

Figure 7. Velocity (y-component) mean (top) and standard deviation (bottom) cross sections on the C-line. Here $\mathrm{x}=0$ at the shelf break (depth $=170 \mathrm{~m})$. Green and red dots indicate locations of ADCPs and CPIESs, respectively. Open circles indicate locations of PIESs $40 \mathrm{~km}$ downstream from the C-line. $0.1 \mathrm{~m} / \mathrm{s}$ contour interval; zero contour white.

\subsection{Mean Velocity Structure}

[26] Using the CPIES and ADCP data as described in the previous section, C-line flow is determined over a $210 \mathrm{~km}$ span from a point $15 \mathrm{~km}$ shoreward of the shelf-break to a site near the Ryukyu Island chain. Figure 7 displays the mean velocity cross section (upper panel) and the standard deviation (lower panel) for the 13-month CPIES + ADCP observation period. The mean cross section shows a region of positive (northeastward) flow containing two local velocity maxima: a surface maximum $(0.65 \mathrm{~m} / \mathrm{s}$, standard deviation $\sigma=0.41 \mathrm{~m} / \mathrm{s}) 30 \mathrm{~km}$ offshore from the shelf break and a subsurface maximum $(0.68 \mathrm{~m} / \mathrm{s}, \sigma=0.15 \mathrm{~m} / \mathrm{s})$ at $170 \mathrm{~m}$ depth, $70 \mathrm{~km}$ from the shelf break. Positive mean velocities extend to the seafloor below this subsurface velocity maximum. In the mean, the subsurface maximum is slightly stronger than the surface maximum. Nevertheless, the highest velocities in the record do occur near the surface which explains why the standard deviation around the surface maximum is three times larger than that around the deeper maximum.

[27] Other authors have observed a subsurface velocity maximum within $150 \mathrm{~km}$ of the C-line in the ECS. Ito et al. [1995] found a subsurface maximum of $\sim 0.7 \mathrm{~m} / \mathrm{s}$ at $250 \mathrm{~m}$ depth using an ADCP on a towed "fish" about $140 \mathrm{~km}$ upstream of the PN-line, and Ichikawa and Beardsley [1993] found a subsurface velocity maximum of $\sim 1 \mathrm{~m} / \mathrm{s}$ at about $200 \mathrm{~m}$ depth using hydrocasts referenced with surface ADCP and GEK measurements near the PN-line.

The subsurface-maximum structure, however, is not obvious in mean velocity sections from Oka and Kawabe's [2003] hydrographic and shipboard ADCP measurements or from Guo et al., 's [2006] numerical models.

[28] There are two regions of mean negative flow: a deep countercurrent over the continental slope and a recirculation further offshore which extends throughout the water column. These features have been reported by other authors [e.g., Bingham and Talley, 1991; Ichikawa and Beardsley, 1993; Ito et al., 1995; James et al., 1999; Oka and Kawabe, 2003]. Figure 7 and the near-bottom velocities measured by the ADCPs and CPIES current sensors (Table 1) show that, in the mean, the countercurrent at $\mathrm{C} 1$ and $\mathrm{C} 2$ does not extend over the shelf to A1 and barely reaches A2 (mean at A2 is $-0.3 \mathrm{~cm} / \mathrm{s} 15 \mathrm{~m}$ above the seafloor and positive at higher elevations).

[29] The mean velocity cross section along the PN-line reported by Oka and Kawabe [2003] (their Figure 3a) does not show vertical shear in the recirculation as strong as that in Figure 7. We verified that our vertical shear is not an artifact resulting from the use of two separate GEMs (the main GEM and the C6 "warm" GEM, section 3.1.1.) to generate $\delta$ profiles. Even when a single GEM generated from all of the hydrocasts in the ECS (but including only the upper $700 \mathrm{~m}$ of the "warm casts") is used to determine $\delta$ profiles, the shear in the recirculation is still present. In addition, calculations based only on the mean travel times at C5 and C6, without an OI mapping step, result in strong vertical shear although in this case the shear is located between $\mathrm{C} 5$ and $\mathrm{C} 6$ rather than at the eastern edge of the instrument array. These tests indicate that while the vertical shear is real, its horizontal structure is uncertain since the instrument spacing on this end of the line is $40 \mathrm{~km}$. Note, however, that the $\mathrm{C}$-line cross section shown in Figure 7 has the P-line instruments' $x$-positions (see Table 1) superimposed on it (open circles). Instruments from the P-line were used in OI mapping $\tau$ (described in section 3.1.2). Since this line, which is $40 \mathrm{~km}$ downstream of the C-line, falls within the empirically determined $\tau$ correlation length scale $(55 \mathrm{~km})$, the P-line data help determine the location of this vertical shear.

\subsection{Velocity Variations}

[30] While the mean velocity cross section in Figure 7 shows surface and deep velocity maxima of comparable strength coexisting, the velocity cross section time series generated from the 2-d lowpass filtered data shows variability in the Kuroshio velocity structure. Examples of velocity cross section snapshots are shown in Figure 8, including the days with the highest and lowest recorded net transports (Figures $8 \mathrm{~b}$ and $8 \mathrm{c}$, respectively). Snapshots from 8 March 2004 (Figure 8a) and 9 September 2004 (Figure 8d) have no localized subsurface maximum; the strongest jet is confined to the surface. In contrast, snapshots from 28 April 2004 (Figure 8b) and 5 June 2004 (Figure 8c) do have localized subsurface maxima. On 28 April the subsurface maximum is stronger than the surface maximum $(1.1 \mathrm{~m} / \mathrm{s}$ compared to $0.7 \mathrm{~m} / \mathrm{s})$ while on 5 June the maxima are comparable $(0.4 \mathrm{~m} / \mathrm{s}$ surface maximum and $0.3 \mathrm{~m} / \mathrm{s}$ subsurface maximum). EOF analysis of the time-varying velocity structure is reported elsewhere [Lim, 2008]. 

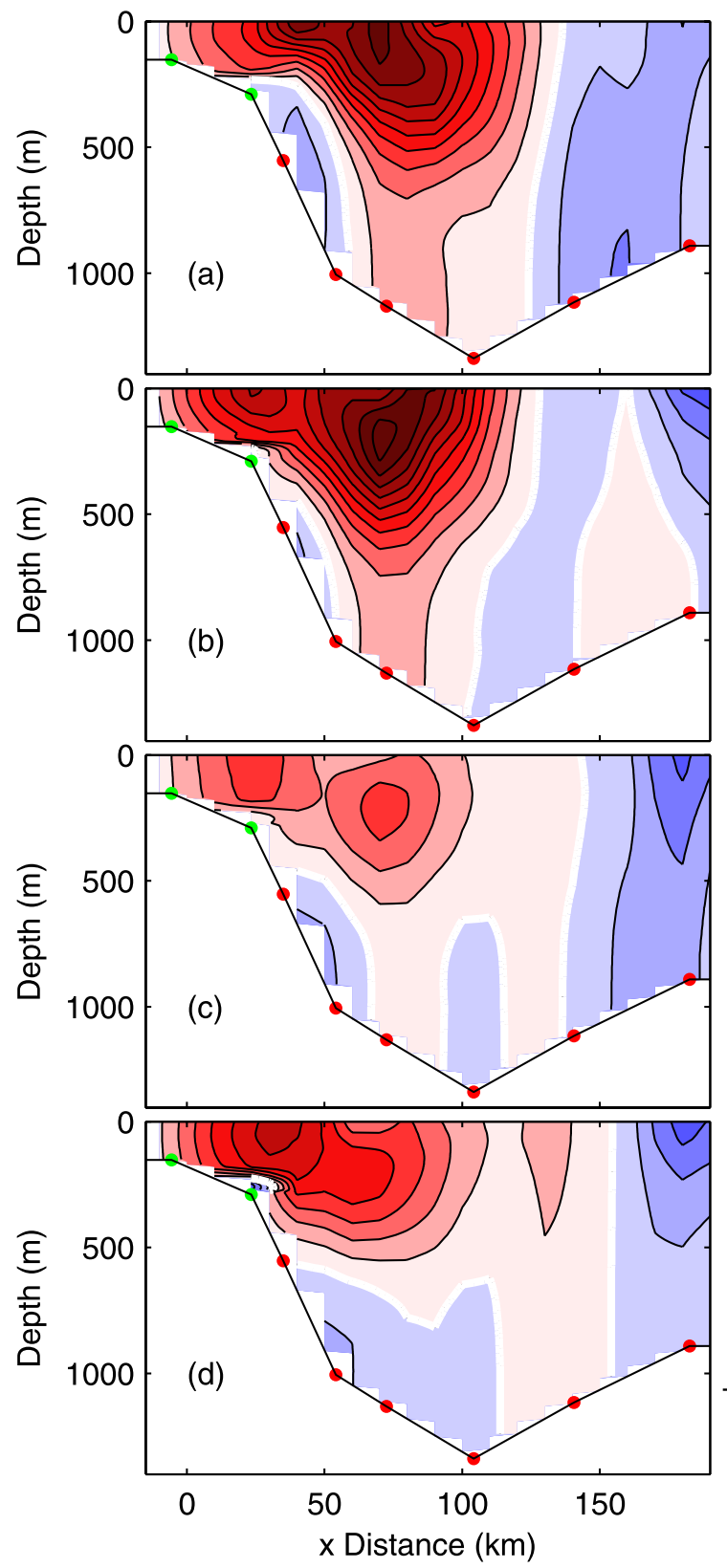

$\mathrm{m} / \mathrm{s}$
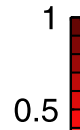

0.5

0

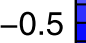

$-0.5$ $-1$

Figure 8. Velocity (y-component) snapshots. Here $\mathrm{x}=0$ at the shelf break $($ depth $=170 \mathrm{~m})$. Green and red dots indicate locations of ADCPs and CPIESs, respectively. Contour interval is $0.1 \mathrm{~m} / \mathrm{s}$, zero contour white. (a-d) 8 March, 28 April, 5 June, and 9 September 2004, respectively.

[31] The depth of the overall maximum velocity is bimodally distributed with occurrence peaks at the surface and 210 dbar (Figure 9). The overall velocity maximum is deeper than $80 \mathrm{dbar} 47 \%$ of the time. It is interesting to note that while the deep frequency peak is at $210 \mathrm{dbar}$, the location of the subsurface maximum in the mean cross section (Figure 7) is shallower at 170 dbar.

[32] When the highest velocities are in the layer between the surface and $80 \mathrm{dbar}$, the maxima range between $0.36 \mathrm{~m} / \mathrm{s}$ and $2.02 \mathrm{~m} / \mathrm{s}$ and the standard deviation of the velocity maximum's $x$-position is $17 \mathrm{~km}$. When the highest velocities are deeper than $80 \mathrm{dbar}$, the maxima range between
$0.31 \mathrm{~m} / \mathrm{s}$ and $1.11 \mathrm{~m} / \mathrm{s}$ and the standard deviation of the velocity maximum's $x$-position is $14 \mathrm{~km}$.

[33] In the mean cross section shown in Figure 7, the countercurrent is primarily confined between $\mathrm{C} 1$ and $\mathrm{C} 2$. The snapshots in Figure 8, however, show that the position of the countercurrent moves on- and offshore and occasionally reaches beyond $\mathrm{C} 3$, although the near-bottom velocity measured by the $\mathrm{C} 3$ current sensor is negative for only $6 \%$ of the 23-month record. Since the countercurrent width is comparable to the instrument spacing over the slope, our data do not adequately resolve this countercurrent.

[34] Nitani [1972] suggested using the location of the $18^{\circ} \mathrm{C}$ isotherm at $200 \mathrm{dbar}$ as an indicator of ECS Kuroshio position (i.e., location of maximum surface velocity). Our data show what previous authors [e.g., Su et al., 1990] have pointed out, namely, that the maximum surface velocity often falls shoreward of the $200 \mathrm{dbar}$ isobath, and thus the location of an isotherm at 200 dbar is not always a useful proxy for Kuroshio position. Guan [1980] defined the "core" of the Kuroshio as the region between the surface $0.4 \mathrm{~m} / \mathrm{s}$ isotachs. We have adopted this definition of the "core" and take its midpoint to be the "position" of the Kuroshio. (Using the maximum surface velocity location results in a "jumpy" time series of position due to the difficulty in resolving the exact location of a maximum with instruments spaced $\sim 20 \mathrm{~km}$ apart.)

[35] Figure 10 shows the time series of surface velocity across the C-line with the $0.4 \mathrm{~m} / \mathrm{s}$ isotachs drawn in black and position in yellow. With this definition, the mean core width over 13 months is $75 \mathrm{~km}$, comparable to the widths of $70-110 \mathrm{~km}$ observed by Guan [1980] with GEK measurements. Occasionally, the core (thus defined) disappears altogether, such as early June 2004 (Figure 10). During these periods $(0.88 \%$ of the total) we interpolate the position time series. The maximum Kuroshio width was $121 \mathrm{~km}$ on 1 March 2004. The position of the Kuroshio core varies between $x=21 \mathrm{~km}$ on 27 October 2004 and $x=93 \mathrm{~km}$ on 13 August 2004. On the basis of the 13 month measurements, the mean position is $x=52 \pm 2 \mathrm{~km}(\sigma=13 \mathrm{~km})$. The maximum surface velocity varies between $0.31 \mathrm{~m} / \mathrm{s}$ on 4 June 2004 and $2.02 \mathrm{~m} / \mathrm{s}$ on 5 January 2004, with an average of $0.78 \mathrm{~m} / \mathrm{s}$.

\subsection{Mean Transport}

[36] From the full 23 months of measurements, the mean net absolute transport across the $\mathrm{C}$-line is estimated to be

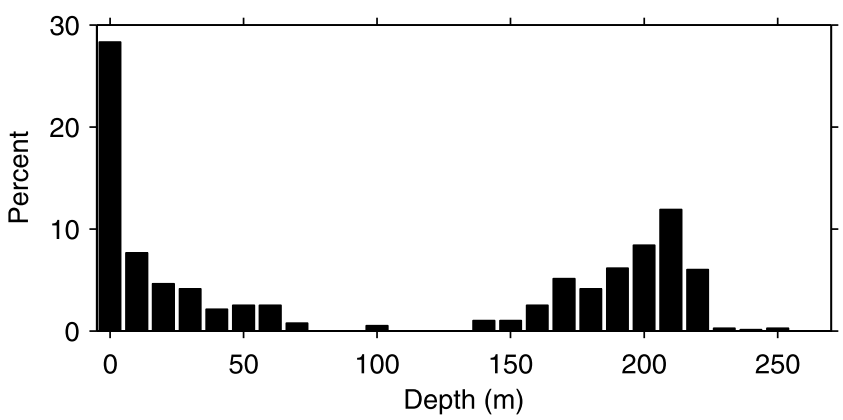

Figure 9. Histogram of depth of overall maximum velocity. 


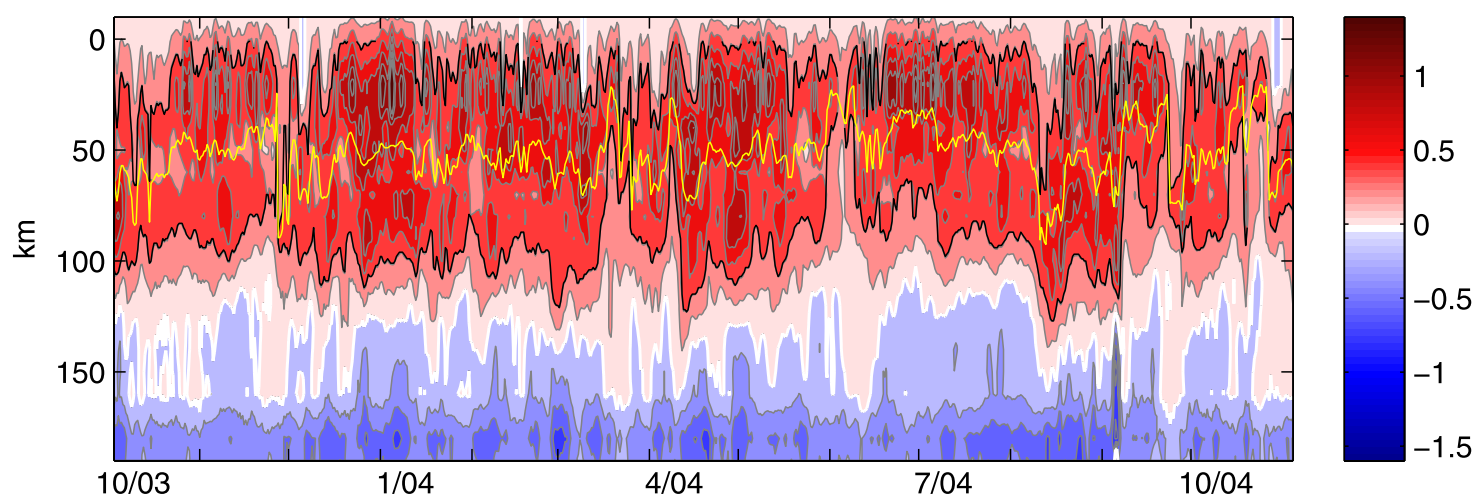

Figure 10. Surface velocity (y-component) across C-line shown on a t-x plot of surface velocity (ycomponent) across the C-line. Zero contour is white. Contour interval is $0.2 \mathrm{~m} / \mathrm{s}$. Black lines are edges of the Kuroshio "core" according to the definition of Guan [1980] and yellow line, midway between the black lines, is our "Kuroshio position." Distances are given relative to the shelf-break (170 m depth). Tick marks indicate beginnings of months.

$18.7 \pm 0.5 \mathrm{~Sv}(\sigma=4.0 \mathrm{~Sv})$. This is very similar to the mean estimated from the 13 months for which the most reliable shelf transport values are available, $18.5 \pm 0.8 \mathrm{~Sv}(\sigma=$ 4.0 Sv). Means are summarized in Table 2.

[37] The mean net transport is about $3 \mathrm{~Sv}$ smaller than that reported by Johns et al. [2001] for flow into the ECS east of Taiwan. Their 20-month mean absolute transport from September 1994 to May 1996 is 21.5 Sv. Also their maximum transport (33 Sv) and minimum $(12 \mathrm{~Sv})$ are both larger than the extrema observed in this study (section 4.4). While this discrepancy in the means may reflect interannual variability in Kuroshio strength, it also may indicate that the system is not closed between the Ilan Ridge and the C-line with flow onshelf and/or leakage through the Ryukyu Island chain.

[38] In a fine-resolution numerical model, Guo et al. [2006] estimated the time-averaged Kuroshio onshelf transport across the $200 \mathrm{~m}$ isobath in the ECS between the region east of Taiwan and west of Kyushu to be about $1.46 \mathrm{~Sv}$ with maximum $(\sim 3 \mathrm{~Sv})$ in fall and minimum $(<0.5 \mathrm{~Sv})$ in summer. The model-derived fall onshelf transport is consistent with that inferred from observation [Teague et al., 2003]. South of the PN-line, the model's onshelf transport is about 1.6 Sv [Guo et al., 2006]. Observations indicate that flow is driven onshelf by a permanent cyclonic eddy north of Taiwan [Su et al., 1990; Wong et al., 2000] and by warm rings and filaments shed by Kuroshio meanders with wavelengths of $100-150 \mathrm{~km}$ and periods of $14-20 \mathrm{~d}$ propagating over the shelf-slope, observed in satellite infrared images [Qiu et al., 1990]. Further evidence of upwelling onto the shelf related to the propagating meanders comes from towed ADCP measurements taken just southwest of the PN-line where horizontal convergence over the slope results in vertical velocities up to $2.8 \mathrm{~cm} / \mathrm{s}$ [Ito et al., 1995].

[39] In addition to the onshelf flow, there may be flow from the ECS into the Philippine Basin through the Ryukyu Islands south of the C-line, perhaps through the Kerama Gap, but the strength, and even the direction, of that flow have not been measured. Model results exhibit a southward leakage of about $0.7 \mathrm{~Sv}$ through the Ryukyu Island chain
[Guo et al., 2006] south of the PN-line (our C-line). Considering this leakage and onslope transport of the Kuroshio south of the C-line, the difference in mean transports into (from Johns et al. [2001]) and within the ECS (from this study) is reduced to about $0.5 \mathrm{~Sv}$. This difference could be due to interannual variation or errors in estimating the transport over the shelf and slope.

[40] For the period when ADCP data are available on the shoreward edge of the Kuroshio, net absolute transport can be divided into the positive (northeastward) and negative portions of flow (Figure 7). (The negative transport in the recirculation can be determined for the entire 23 months, since it is always within the area measured by the IESs.) The 13-month combined mean negative transport is $-5.4 \pm$ $0.3 \mathrm{~Sv}$ of which the major part $(\sim 91 \%)$ is the recirculation in the eastern side of the channel. The mean positive transport is $24.0 \pm 0.9 \mathrm{~Sv}$ and shows greater variability ( $\sigma=$ $4.4 \mathrm{~Sv})$ than the combined negative transport $(\sigma=1.8 \mathrm{~Sv})$.

Table 2. Mean Transports (Sv) for the Two Periods December 2002 to November 2004 and November 2003 to November 2004

\begin{tabular}{|c|c|c|c|c|c|c|}
\hline \multirow[b]{3}{*}{ Net absolute transport } & \multicolumn{6}{|c|}{ Averaging Period } \\
\hline & \multicolumn{3}{|c|}{ 23-Month } & \multicolumn{3}{|c|}{ 13-Month } \\
\hline & 18.7 & $0.5^{\mathrm{a}}$ & $4.0^{\mathrm{a}}$ & 18.5 & 0.8 & 4.0 \\
\hline Positive absolute transport & $\mathrm{nd}^{\mathrm{b}}$ & & & 24.0 & 0.9 & 4.4 \\
\hline $\begin{array}{l}\text { Negative absolute transport } \\
\text { in countercurrent }\end{array}$ & $\mathrm{nd}^{\mathrm{b}}$ & & & -0.5 & 0.1 & 0.4 \\
\hline $\begin{array}{l}\text { Negative absolute transport } \\
\text { in recirculation }\end{array}$ & -5.3 & 0.3 & 2.1 & -4.9 & 0.3 & 1.8 \\
\hline Baroclinic transport $^{\mathrm{c}}$ & 12.8 & 0.4 & 2.8 & 12.6 & 0.6 & 2.9 \\
\hline Barotropic transport ${ }^{\mathrm{c}}$ & 1.6 & 0.2 & 2.4 & 1.6 & 0.3 & 2.3 \\
\hline
\end{tabular}

${ }^{\mathrm{a} B}$ Beside each mean, the mean standard error (left) and standard deviation (right) are listed.

'Because of the lack of ADCP data during the first 10 months, 23-month values are unavailable ("nd" refers to "no data").

${ }^{\mathrm{c}}$ Baroclinic and barotropic transports (referenced to $700 \mathrm{dbar}$ ) are reported only for transport across the $160 \mathrm{~km}$ measured by $\mathrm{C} 1$ through $\mathrm{C} 6$. Using the definitions of Ichikawa and Beardsley (1993), the 13 month mean "baroclinic" and "barotropic" (positive) transports across the entire Cline are $9.9 \mathrm{~Sv}$ and $14.1 \mathrm{~Sv}$, respectively; across the $160 \mathrm{~km}$ measured by $\mathrm{C} 1$ and C6 they are $9.0 \mathrm{~Sv}$ and $10.9 \mathrm{~Sv}$, respectively. 


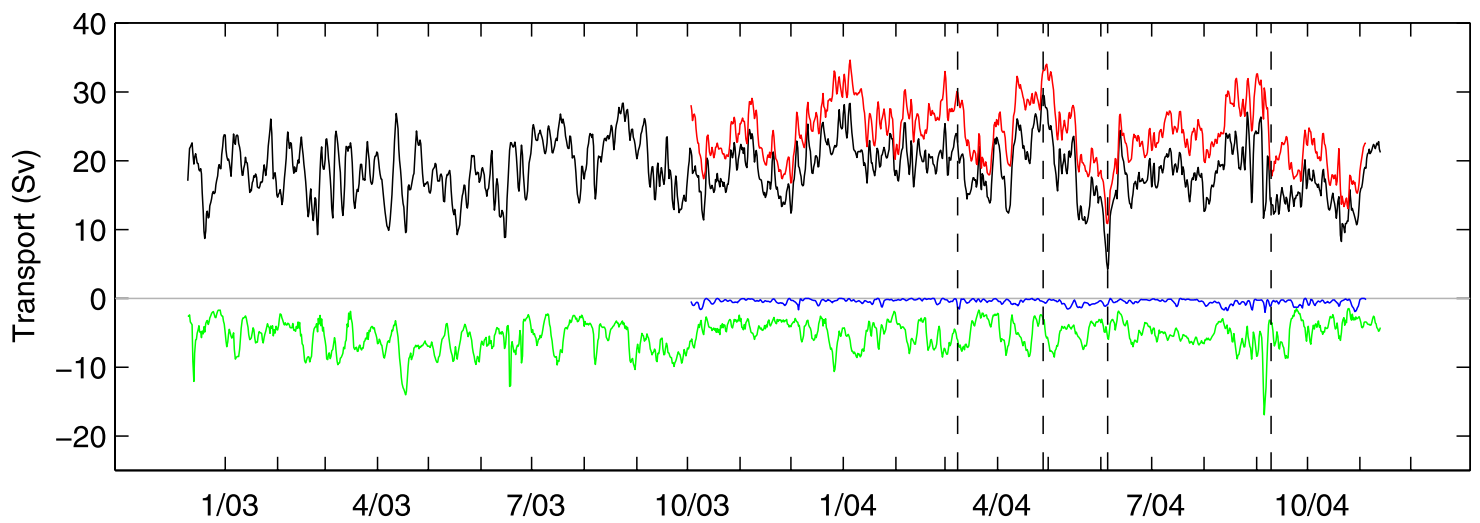

Figure 11. Absolute transports across the C-line: red represents positive, blue represents negative onslope (countercurrent), green represents negative offslope (recirculation), and black represents net. Tick marks denote the beginning of each month. Dashed lines show times of velocity snapshots plotted in Figure 8 .

Relative to their respective means, however, the negative transport variability is stronger by a factor of 2 . Our mean positive transport is similar to that reported by Ichikawa and Beardsley [1993], 23.7 $\pm 2.0 \mathrm{~Sv}$ (their "KVT" which is the integral of all positive velocities along the section).

[41] Net absolute transport measured by the CPIESs can also be split into baroclinic (referenced to $700 \mathrm{dbar}$ ) and barotropic components. The 23-month mean baroclinic transport measured by $\mathrm{C} 1$ through $\mathrm{C} 6$ (160 km of the C-line) is 12.8 Sv; the mean barotropic transport is $1.6 \mathrm{~Sv}$. The barotropic component is only $11 \%$ of the total mean transport. A fine resolution numerical model [Guo et al., 2003] also predicts a barotropic component (consistent with the definition used here) which is $11 \%$ of the total transport. While this small barotropic component would seem to justify the assumption, made in previous ECS studies [e.g., Hinata, 1996], that the baroclinic transport referenced to 700 dbar calculated from hydrography is a reasonable estimate of total transport, this is not necessarily the case at a particular time. As can be seen from the time series in Figure 4 , the baroclinic and barotropic transports vary considerably in time. The two are nearly equal on 18 July 2004.

[42] In Ichikawa and Beardsley's [1993] study of the positive flow (KVT) of the Kuroshio in the ECS, they defined baroclinic transport (BCKVT) as the positive flow in excess of the depth-averaged flow and the barotropic transport (BTKVT) as the difference between the KVT and the BCKVT. They found that the ratio of barotropic to baroclinic mean flow in the positive transport is about 3:1 near our C-line. According to their definitions, this ratio is $3: 2$ in our study.

[43] In the above discussions, all transports were calculated by integrating velocity from the surface to the seafloor where the depths were determined by interpolating the bathymetry data of Choi et al. [2002] onto a straight line running at $38^{\circ}$ through the shelf break $\left(28.536^{\circ} \mathrm{N}\right.$, $126.723^{\circ} \mathrm{E}$ ). Since the instrument locations deviate slightly from a straight line, this results in some discrepancies between the integration depth and the actual instrument depth. Alternatively, seafloor depths can be estimated by simply linearly interpolating the depth between instruments. This increases the net transport by $0.1 \mathrm{~Sv}$. Amongst the components of the net transport (positive flow, countercurrent and recirculation) the largest effect is in the recirculation whose magnitude is increased by $0.5 \mathrm{~Sv}$.

[44] There is a small component of transport in the ECS which is not captured here, namely that flowing across the $25 \mathrm{~km}$ between the southeastern end of the C-line and the Ryukyu Island chain. If the velocity goes to zero linearly from the end of the $\mathrm{C}$-line to the island chain, we are missing about $-1.3 \mathrm{~Sv}$ of the recirculation transport. Some of this may be southward flowing water that has seeped through the island chain rather than recirculation of Kuroshio water in the ECS.

\subsection{Transport Variations}

[45] Time series of absolute transports across the C-line are shown in Figure 11. The overall maximum net transport was 29.5 Sv on 28 April 2004, followed 38 d later by the overall minimum of $4.0 \mathrm{~Sv}$ on 5 June 2004. This may be related to a Kuroshio path transition to the large meander state south of Honshu, Japan, which occurred in July 2004 [Qiu and Chen, 2005, Figure 7a].

[46] Previous studies have reported that Kuroshio transport in the ECS is typically highest in summer and lowest in autumn (Fujiwara et al. [1987] and Hinata [1996], both reporting transports referenced to 700 dbar; Ichikawa and Beardsley [1993], reporting absolute transport). These results were based on snapshots of the transport each season over many years. When the transports from the present study are averaged by season (Figure 12, crosses), the highest transport is indeed in summer $(19.6 \mathrm{~Sv})$ but the fall transport $(18.3 \mathrm{~Sv})$ is the second lowest; the lowest transport $(17.6 \mathrm{~Sv})$ is in spring.

[47] Kawabe [1988] investigated the seasonality of the Kuroshio as it exits the ECS through the Tokara Strait by using sea-level difference from tide-gage data at Naze and Nishinoomote as a proxy for transport. For 19 years (19651983) averaged by month, the maximum sea level difference (and by inference the maximum transport) was in July and the minimum in October. However, the character of seasonal signal varied between years and was split into four types by Kawabe: small-amplitude, semiannual, and annual signals with two different phases. Monthly averaged trans- 


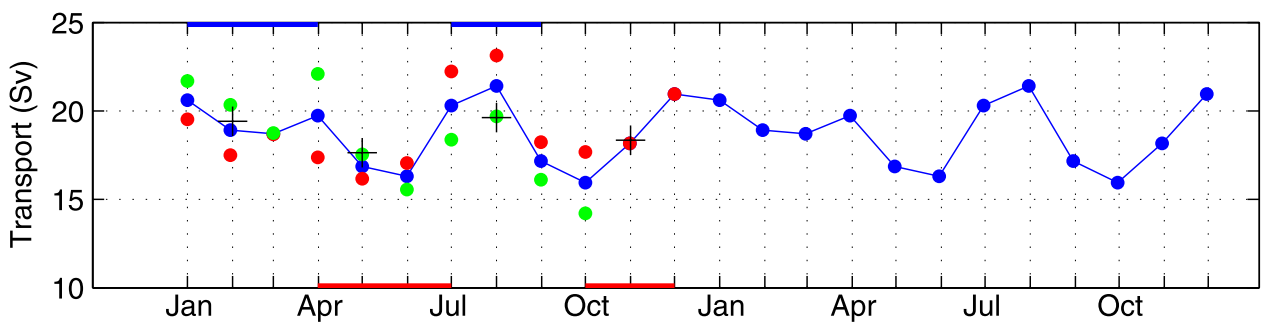

Figure 12. Mean net absolute transport. Red dots represent monthly means for the first year; green dots represent monthly means for the second year; blue dots represent monthly means for the 2 years averaged together (these are plotted and joined over a two year period to show clearly the yearly cycle). Plus symbols represent seasonal (3-month) means for the 2 years averaged together. Complete data for November and December are only available for the first year. Red and blue bands show periods of Kawabe's [1988] semiannual-type minima and maxima, respectively (see text).

ports for the present study are shown in Figure 12. When monthly mean net absolute transports are calculated as an average of all data values falling within a given month over the two-year period, the highest transport is in August $(21.4 \mathrm{~Sv})$ and the lowest is in October $(15.9 \mathrm{~Sv})$, which is close to the 19-year mean result reported by Kawabe. The seasonal signal in the data from the current study most closely (though not exactly) resembles Kawabe's semiannual type which has maxima occurring January to April and July to September and minima falling in April to June and October to November.

\section{Conclusions}

[48] Near the PN-line north of Okinawa, we have obtained transport and velocity cross section time series lasting nearly 2 years. These show net absolute transport varying between about $4 \mathrm{~Sv}$ and $30 \mathrm{~Sv}$ with a $19 \mathrm{~Sv}$ mean value. While the maximum and mean transports are comparable to those reported previously, the minimum transport from this study is lower than any transport from previous studies [Johns et al., 2001, and references therein]. The seasonal signal of transport from this study most closely resembles Kawabe's [1988] semiannual-type with monthly mean transport minima in both years occurring in May/June and October. Surface velocities reach $2 \mathrm{~m} / \mathrm{s}$ and the Kuroshio position varies through $70 \mathrm{~km}$. These findings are consistent with previous work in the ECS.

[49] The bimodal distribution of the depth of overall velocity maximum has not been reported previously. With occurrence peaks at the surface and $210 \mathrm{~m}$ depth, over 13 months, the maximum velocity is deeper than $80 \mathrm{~m}$ nearly half of the time and occurs between $80 \mathrm{~m}$ and $130 \mathrm{~m}$ less than $1 \%$ of the time. The existence of a subsurface velocity maximum, has been reported in some, but not all, previous studies of this region. It may be absent in some studies because (1) the subsurface velocity maximum is ephemeral and may not be present in an isolated cross section, (2) a local maximum may be missed if instrument spacing is not sufficiently dense as demonstrated by the analysis of Ichikawa and Beardsley [1993], or (3) the subsurface maximum has a significant barotropic component and may not be represented in the baroclinic field alone. This third possibility is demonstrated in Figure 13 which shows the mean velocity determined from the IES instruments split into the baroclinic shear (relative to $700 \mathrm{dbar}$ ) and the barotropic reference velocity.

[50] Modeling by Nakamura [2005] suggests that the shape of the velocity cross section (e.g., position of surface velocity maximum and rate of velocity decrease with depth), rather than the magnitude of the transport, determines whether most of the Kuroshio leaves the ECS through the northern or southern section of the Tokara Strait. This in turn is thought to influence the large meander state of the Kuroshio south of Japan [Oka and Kawabe, 2003]. Nakamura's [2005] study was performed using a shape formula from Xue and Mellor [1993] having a single velocity maximum at the surface. It would be interesting to determine the effect of a subsurface maximum on the modeled path of the Kuroshio as it exits the ECS.

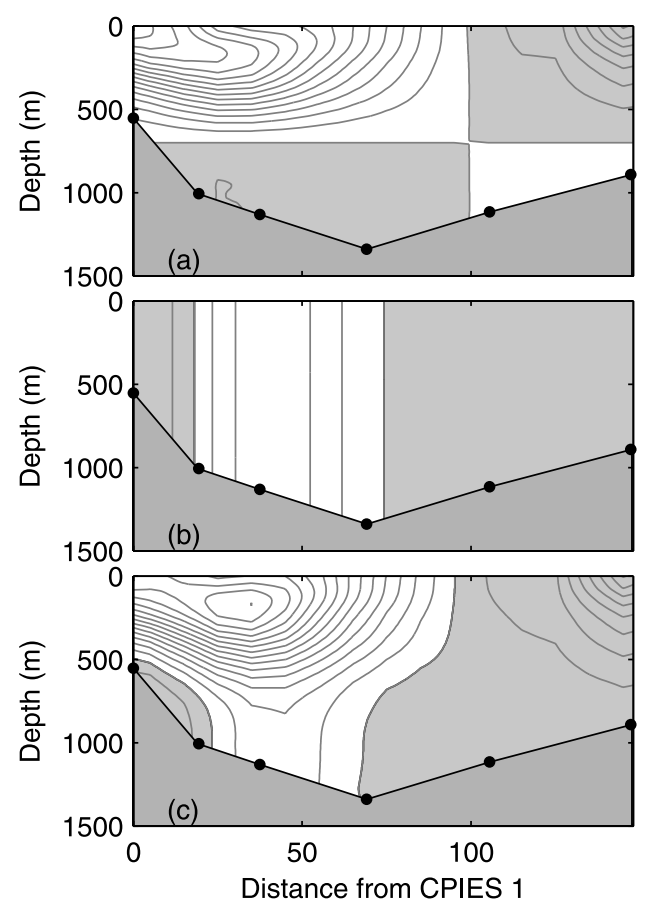

Figure 13. Mean absolute velocity (bottom panel) split into the shear (top panel) and the reference velocity (middle panel). The bottom panel is the sum of the two upper panels. Negative velocities are shaded grey. Contour interval is $5 \mathrm{~cm} / \mathrm{s}$. Black dots represent CPIES locations. 

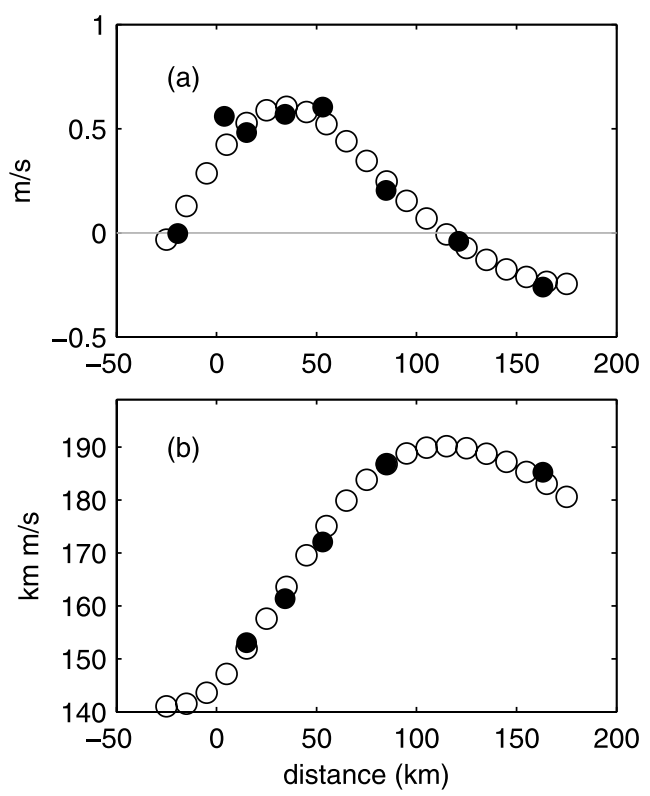

Figure A1. OI map of $150 \mathrm{~m}$ mean fields: (a) velocity, (b) streamfunction. Closed circles are input data, and open circles are OI mapped data.

[51] This study confirms the presence of a persistent countercurrent beneath the Kuroshio. Notably the nearbottom velocity at site $\mathrm{C} 2$ measured by the CPIES current sensor is in the downstream direction for only $26 \%$ of the 23 -month record and its mean value is $-3 \mathrm{~cm} / \mathrm{s}$ More densely spaced instruments are required to study the structure of this countercurrent since it is typically only $20-30 \mathrm{~km}$ wide. While there is certainly a countercurrent present, in order to capture (1) nongeostrophic dynamics and (2) dynamics associated with higher-mode vertical structure one would need to deploy current sensor moorings over the slope. This study helps determine where such an instrument array should be deployed. H. Nakamura et al. (submitted manuscript, 2008) used current meters to measure velocity in the countercurrent 100 and $200 \mathrm{~m}$ above the bottom at four ECS sites in water about $700 \mathrm{~m}$ deep. Their observations show velocities and directions were more variable than those recorded by us at site $\mathrm{C} 2$, suggesting that their measurements were somewhat shoreward of the persistent countercurrent.

[52] Subsequent papers will present statistical analyses (spectra, cross-spectra, cross-correlations, etc.) of the variabilities and interrelationships of these time series and those of other regional quantities such as the Kuroshio Position Index representing the path of the Kuroshio in the Tokara Strait [Kawabe, 1995], Ryukyu Current, and Korea/Tsushima Strait transports.

\section{Appendix A: Extrapolation Methods}

\section{A1. Spatial Extrapolation by Vertical Extension}

[53] The first method for spatial extrapolation of the ADCP data uses a GEM lookup table (with $150 \mathrm{~m}$ streamfunction $\Psi_{150}$, rather than $\tau_{700}$, as the lookup index) to obtain vertical extensions of the velocity profiles in the manner described below.

\section{A1.1. Input Data}

[54] From the ADCP A1 and A2 time series, one can extract $V_{150}$, the time series of absolute velocity at $150 \mathrm{~m}$ depth. (At A1, measurements of $V_{150}$ were used directly; at A2, $V_{150}$ was determined by extrapolation from $179 \mathrm{~m}$ to $150 \mathrm{~m}$ depth using a spline fit to the measured velocity profile.) Likewise, time series of $V_{150}$ at $\mathrm{C} 1-\mathrm{C} 6$ are known from OI mapping of $\tau_{\text {ref }}$ and bottom pressure data (leveled with near-bottom current measurements). At each CPIES site the time series of absolute streamfunction at $150 \mathrm{~m}$, $\Psi_{150}$, can be calculated:

$$
\Psi_{150}=\frac{\Phi_{700}^{150}}{f}+\frac{P}{\rho f},
$$

where $\Phi_{700}^{150}=-\int_{700}^{150} \delta d p$ is the geopotential anomaly of the 150 dbar surface ${ }^{700}$ relative to the 700 dbar surface. This is readily determined from $\tau_{\text {ref }}$ using the GEM lookup table. The second term on the right-hand side of this equation represents change in mass of the water column above the $700 \mathrm{dbar}$ level. This is determined directly from the leveled pressure-sensor data.

[55] The absolute velocity normal to the line of instruments is given by the gradient of the absolute streamfunction:

$$
\frac{\partial \Psi_{150}}{\partial x}=-V_{150}
$$

[56] Using $V_{150}$ at all sites and $\Psi_{150}$ at the CPIES sites as input data, OI mapping is used to determine the time series of $\Psi_{150}$ at sites $\mathrm{A} 1$ and $\mathrm{A} 2$ as described next.

\section{A1.2. Mapping the Mean Field and the Residual}

[57] The OI mapping is done in two steps. Streamfunction and velocity are decomposed into the time-mean and a residual:

$$
\begin{aligned}
& \Psi_{150}(x, t)=\bar{\Psi}_{150}(x)+\Psi_{150}^{\prime}(x, t) \\
& V_{150}(x, t)=\bar{V}_{150}(x)+V_{150}^{\prime}(x, t),
\end{aligned}
$$

where the overbar represents a time average over the duration, $T$, of the measurements.

[58] The time-mean fields are mapped using a relatively large correlation length scale $(85 \mathrm{~km})$. The resulting mean fields are plotted in Figure A1. Note that the velocity plot is simply the first derivative of the streamfunction plot.

[59] In the second OI step, the residual is mapped using a shorter correlation length scale of $35 \mathrm{~km}$. This correlation length scale was determined from a plot (not shown) of correlation coefficient versus distance for pressure data with the common-mode signal removed. At each time, $t$, when $\Psi_{150}^{\prime}(x, t)$ has been determined, the mean field, $\bar{\Psi}_{150}(x)$, is added to produce, by the first of these two equations, the time series of absolute streamfunction, $\Psi_{150}(x, t)$.

\section{A1.3. Lookup Table}

[60] The next step in determining the velocity profiles at sites $\mathrm{A} 1$ and $\mathrm{A} 2$ is to relate the streamfunction to the 
specific volume anomaly, $\delta$. The absolute streamfunction can be separated into baroclinic and barotropic components:

$$
\Psi_{150}=\Psi_{b c}+\Psi_{b t}
$$

Assuming $\Psi_{150} \approx \Psi_{b c}$ gives

$$
\Phi_{700}^{150} \approx f \Psi_{150}
$$

[61] This assumption is a potential source of error, but its validity was verified by good agreement between the shapes of those portions of the velocity profiles measured by the ADCPs (from 30 to $152 \mathrm{dbar}$ and 179 to $285 \mathrm{dbar}$ for sites A1 and A2 respectively) with those calculated by the procedure described here.

[62] From hydrographic data, a GEM lookup table relating $\delta$ profiles and $\Phi_{700}^{150}$, is constructed. Using this lookup table, a time series of specific-volume-anomaly profiles is determined from the streamfunction time series.

[63] Finally, the horizontal gradients in $\delta$ profiles were used to determine vertical shears of velocity at sites A1 and A2. These shears were then referenced with the $V_{150}$ values, and the transport over the upper slope and shelf was calculated (Figure 5 blue line) by integrating the velocities.

\section{A2. Spatial Extrapolation by Horizontal Smoothing}

[64] The second method for spatial extrapolation of the ADCP profiles assumes that velocity varies smoothly along horizontal surfaces between $\mathrm{C} 1$ and $\mathrm{A} 1$, separated by about $41 \mathrm{~km}$. The velocity profile at $\mathrm{C} 1$ was estimated from the CPIES, as described in section 3.1.2. At A1 a mixed layer in the upper $30 \mathrm{~m}$ of the water column was assumed and the shallowest velocity measurement was simply projected up to the surface. Velocity measurements at A1 together with velocity and pressure at the CPIES sites were used as input to an OI mapping of the absolute stream function, $\Psi_{i}$, at each level, $i$, in $10 \mathrm{~m}$ increments between $150 \mathrm{~m}$ depth and the surface. The OI procedure was done in two steps: first the mean fields and then the residuals (at 12-hour intervals) were mapped. Once $\Psi_{i}$ was mapped over the upper slope and shelf, the horizontal $\Psi_{i}$ gradient was used to calculate an absolute velocity time series at A2 for that level. The A2 velocities calculated at each level between $150 \mathrm{~m}$ and the surface were then combined with the measured A2 velocities to obtain complete profiles. A2 velocities between $180 \mathrm{~m}$ (highest level measured by the ADCP) and $150 \mathrm{~m}$ (lowest level determined by horizontal smoothing) were linearly interpolated to avoid vertical discontinuity in the velocity profiles. The resulting transport time series is plotted in Figure 5 (green line).

\section{A3. Temporal Extrapolation Using an Analytical Shape Formula}

[65] James et al. [1999] developed an analytical shape formula, based on that of Xue and Mellor [1993], to describe the Kuroshio basic state velocity cross section, $V_{c}(x, z)$ :

$$
V_{c}(x, z)=V_{\mathrm{o}} \exp \left(z / Z_{e}\right) \exp \left(\frac{x-X_{c o}-z / Z_{m}}{L}\right)^{2} .
$$

[66] They empirically determined the constants $\left(V_{o}, Z_{e}\right.$, $\left.X_{c o}, Z_{m}, L\right)$ by fitting to a velocity cross section determined from hydrography referenced with surface ADCP data. Using this formula, an instantaneous Kuroshio velocity cross section, $V(x, z, t)$, can be approximated by shifting this basic state shape horizontally a distance $x_{o}(t)$ and multiplying it by a strength factor, $S(t)$.

[67] The position and strength of the Kuroshio were determined as follows. At each time, $t, x_{o}(t)$, and $S(t)$, were chosen such that $\left[V_{L P}(x, z, t)-S(t) \cdot V_{c}\left(x-x_{o}(t), z\right)\right]^{2}$ was minimized where $V_{L P}$ is the 20-day lowpass-filtered observed velocity (shorter period fluctuations were not well reproduced). This was carried out for the region between $x=$ $35 \mathrm{~km}$ (location of CPIES 1 ) and $x=100 \mathrm{~km}$ near the edge of the recirculation and between the surface and $400 \mathrm{dbar}$. Once the location and strength were determined for a given time in this manner, they were used with the shape formula and constants from James et al. [1999] to estimate velocities over the upper slope and shelf: $V_{e}(x, z, t)=S(t) \cdot V_{c}(x-$ $\left.x_{o}(t), z\right),-15 \mathrm{~m} \leq x \leq 35 \mathrm{~km}$. The velocities were integrated to determine the net transport over the upper slope and shelf.

[68] Acknowledgments. We would like to acknowledge the support and assistance, in deployment and recovery of instruments, of the following captains together with their crews, scientists, supporting staff, and technicians: Capt. Sadao Ishida aboard the R/V Yokosuka of JAMSTEC, Capt. Bong-Won Lee aboard the R/V Onnuri of KORDI, Capt. Sunao Masumitsu aboard the T/V Kagoshima-maru of Kagoshima University, and Capt. Jeoung Chang Kim aboard the R/V Tamyang of Pukyong National University. Michael Mulroney, Gerry Chaplin, and Karen Tracey provided invaluable assistance with IES preparation, deployment, recovery, and data processing. The CTD data used in the GEM calculations were kindly provided by the Nagasaki Marine Observatory, Japan Meteorological Agency. MA, MW, JP, and DRW were supported by ONR grant N000140210271, KC and BL by grants from the United States Office of Naval Research NICOP "Kuroshio Variability on the Shelf of the East China Sea" (KORDI code PI41900), Korea Science and Engineering Foundation (R01-2003-000-10842-0), and the Korea EAST-I program, and WT by ONR grant N0001402WX20881. Helpful suggestions from two anonymous reviewers greatly improved the manuscript.

\section{References}

Andres, M., et al. (2005), East China Sea Kuroshio 2002-2004 data report, GSO Tech. Rep. 2005-02, Graduate Sch. of Oceanogr., Univ. of R. I., Narragansett.

Bingham, F. M., and L. D. Talley (1991), Estimates of Kuroshio transport using an inverse technique, Deep Sea Res., 38(S1), S21-S43.

Book, J. W., M. Wimbush, S. Imawaki, H. Ichikawa, H. Uchida, and H. Kinoshita (2002), Kuroshio temporal and spatial variations South of Japan determined from inverted echo sounder measurements, J. Geophys. Res., 107(C9), 3121, doi:10.1029/2001JC000795.

Bretherton, F. P., R. E. Davis, and C. B. Fandry (1976), A technique for objective analysis and design of oceanographic experiments applied to MODE-73, Deep Sea Res., 23, 559-582.

Choi, B. H., K. O. Kim, and H. M. Eum (2002), Digital bathymetric and topographic data for neighboring seas of Korea (in Korean), J. Korean Soc. Coastal Ocean Eng., 14(1), 41-50.

Fujiwara, I., Y. Hanzawa, I. Eguchi, and K. Hirano (1987), Seasonal oceanic conditions on a fixed line in the East China Sea, Oceanogr. Mag., 37, 37-46.

Guan, B. (1980), Some results from the study of the variation of the Kuroshio in the East China Sea, In The Kuroshio IV, pp. 897-911, Saikon Publ., Tokyo.

Guo, X., H. Hukuda, Y. Miyazawa, and T. Yamagata (2003), A triply nested ocean model for simulating the Kuroshio - Roles of horizontal resolution on JEBAR, J. Phys. Oceanogr., 33, 146-169.

Guo, X., Y. Miyazawa, and T. Yamagata (2006), The Kuroshio onshore intrusion along the shelf break of the East China Sea: The origin of the Tsushima Warm Current, J. Phys. Oceanogr., 36, 2205-2231.

He, Y. R., D. R. Watts, and K. L. Tracey (1998), Determining geostrophic velocity shear profiles with IESs, J. Geophys. Res., 103(C3), 5607-5622.

Hinata, T. (1996), Seasonal variation and long-term trends of the oceanographic conditions along a fixed hydrographic line crossing the Kuroshio in the East China Sea, Oceanogr. Mag., 45, 9-32. 
Ichikawa, H., and R. C. Beardsley (1993), Temporal and spatial variability of volume transport of the Kuroshio in the East China Sea, Deep Sea Res. I, 40(3), 583-605.

Ichikawa, H., H. Nakamura, A. Nishina, and M. Higashi (2004), Variability of north-eastward current southeast of northern Ryukyu Islands, J. Ocea$n \circ g r$. 60, 351-363.

Ito, T., A. Kaneko, H. Furukawa, N. Gohda, and W. Koterayama (1995), A structure of the Kuroshio and its related upwelling on the East China Sea shelf slope, J. Oceanogr., 51, 267-278.

James, C., M. Wimbush, and H. Ichikawa (1999), Kuroshio meanders in the East China Sea, J. Phys. Oceanogr., 29, 259-272.

Johns, W. E., T. N. Lee, D. Zhang, and R. Zantopp (2001), The Kuroshio east of Taiwan: moored transport observations from the WOCE PCM-1 array, J. Phys. Oceanogr., 31, 1031-1053.

Kawabe, M. (1988), Variability of Kuroshio velocity assessed from the sealevel difference between Naze and Nishinoomote, J. Oceanogr. Soc. Jpn., 44, 293-304

Kawabe, M. (1995), Variations of current path, velocity, and volume transport of the Kuroshio in relation with the large meander, J. Phys. Oceanogr., 25(12), 3103-3117.

Lim, B. H. (2008), Near 60-day variation in the Kuroshio observed in the East China Sea, M.Sc. thesis, 44 pp., Seoul Natl. Univ., Seoul, Korea.

Macdonald, A. M., T. Suga, and R. G. Curry (2001), An isopycnally averaged North Pacific climatology, J. Atmos. Oceanic Technol., 18, $394-$ 420

Meinen, C. S. (2001), Structure of the North Atlantic current in streamcoordinates and the circulation in the Newfoundland basin, Deep Sea Res. I, 48(7), 1553-1580.

Nakamura, H. (2005), Numerical study on the Kuroshio path states in the northern Okinawa Trough of the East China Sea, J. Geophys. Res., 110 C04003, doi:10.1029/2004JC002656.

Nitani, H. (1972), Beginning of the Kuroshio. In: Kuroshio, Physical Aspects of the Japan Current, edited by H. Stommel and K. Yoshida, pp. 129-164, Univ. of Wash. Press, Seattle, Wash.

Oka, E., and M. Kawabe (2003), Dynamic structure of the Kuroshio south of Kyushu in relation to the Kuroshio path variations, J. Oceanogr., 59, $595-608$

Qiu, B., and S. Chen (2005), Variability of the Kuroshio Extension jet, recirculation gyre, and mesoscale eddies on decadal time scales, J. Phys. Oceanogr., 35, 2090-2103, doi:10.1175/JPO2807.1.

Qiu, B., T. Toda, and N. Imasato (1990), On Kuroshio front fluctuation in the East China Sea using satellite and in situ observation data, J. Geophys. Res., 95(C10), 18,191-18,204.

Park, J.-H., D. R. Watts, K. L. Tracey, and D. A. Mitchell (2005), A multiindex GEM technique and its application to the southwestern Japan/East Sea, J. Atmos. Ocean. Tec., 22, 1282-1293.

Park, J.-H., M. Andres, P. Martin, M. Wimbush, and D. R. Watts (2006), Second-mode internal tides in the East China Sea deduced from historica hydrocasts and a model, Geophys. Res. Lett., 33, L05602, doi:10.1029/ 2005GL024732.
Rodrigues, R. (2004), An observational and numerical study of the South Atlantic circulation, Ph.D. dissertation, Graduate Sch. of Oceanogr. Univ. of R. I., Narragansett.

Sibuet, S.-K. Hsu, C.-T. Shyu, and C.-S. Liu (1995), Structural and kinematic evolutions of the Okinawa Trough backarc basin, in Backarc Basins Tectonics and Magmatism, edited by B. Taylor, pp. 343-377, Plenum, New York.

Su, J. L., B. X. Guan, and J. Z. Jiang (1990), The Kuroshio. Part I. Physical features, Oceanogr. Mar. Biol. Annu. Rev., 28, 11-71.

Sun, C., and D. R. Watts (2001), A circumpolar gravest empirical mode for the Southern Ocean hydrography, J. Geophys. Res., 106(C2), $2833-$ 2855.

Teague, W. J., G. A. Jacobs, D. S. Ko, T. Y. Tang, K.-I. Chang, and M.-S. Suk (2003), Connectivity of the Taiwan, Cheju and Korea Straits, Cont. Shelf Res., 23, 63-77.

Watts, D. R., K. L. Tracey, and A. I. Friedlander (1989), Producing accurate maps of the Gulf Stream thermal front using objective analysis, J. Geophys. Res., 94(C6), 8040-8052.

Willeford, B. D. (2001), Using stream function coordinates to study the circulation and water masses of the North Pacific, M.S. thesis, Graduate Sch. of Oceanogr., Univ. of R. I., Narragansett.

Wong, G. T. F., S.-Y. Chao, Y.-H. Li, and F.-K. Shiah (2000), The Kuroshio edge exchange processes (KEEP) study - An introduction to hypotheses and highlights, Cont. Shelf Res., 20, 335-347.

Xue, H., and G. L. Mellor (1993), Instability of the Gulf Stream front in the South Atlantic Bight, J. Phys. Oceanogr., 23, 2326-2350.

Yamashiro, T., and M. Kawabe (2002), Variations of the Kuroshio axis south of Kyushu in relation to the large meander of the Kuroshio, J. Oceanogr., $58,487-503$

Yuan, Y., A. Kaneko, J. Su, X. Zhu, Y. Liu, N. Gohda, and H. Chen (1998), The Kuroshio east of Taiwan and in the East China Sea and the currents east of Ryukyu Islands during early summer of 1996, J. Oceanogr., 54, $217-226$

Zhu, X.-H., I.-S. Han, J.-H. Park, H. Ichikawa, K. Murakami, A. Kaneko, and A. Ostrovskii (2003), The northeastward current southeast of Okinawa Island observed during November 2000 to August 2001, Geophys. Res. Lett., 30(2), 1071, doi:10.1029/2002GL015867.

M. Andres, J.-H. Park, D. R. Watts, and M. Wimbush, Graduate School of Oceanography, University of Rhode Island, Narragansett, RI 02882 1197, USA. (mandres@gso.uri.edu)

K.-I. Chang and B.-H. Lim, Research Institute of Oceanography/School of Earth and Environmental Sciences, Seoul National University, Silimdong Gwanak-gu, Seoul 151-742, South Korea.

H. Ichikawa, Institute of Observational Research for Global Change, Japan Agency for Marine-Earth Science and Technology, 2-15 Natsushima-cho, Yokosuka City, Kanagawa, 237-0061, Japan.

W. J. Teague, Naval Research Laboratory, Code 7332, Stennis Space Center, MS 39529-5004, USA. 